\title{
Treatment of Hepatocellular Carcinoma with Immune Checkpoint Inhibitors and Applicability of First-Line Atezolizumab/Bevacizumab in a Real-Life Setting
}

\author{
Maria Corina Plaz Torres ${ }^{1}$, Quirino Lai ${ }^{2} \mathbb{D}$, Fabio Piscaglia ${ }^{3}\left(\mathbb{D}\right.$, Eugenio Caturelli ${ }^{4}$, Giuseppe Cabibbo ${ }^{5}$, \\ Elisabetta Biasini ${ }^{6}$, Filippo Pelizzaro ${ }^{7}\left(\mathbb{D}\right.$, Fabio Marra ${ }^{8}\left(\mathbb{D}\right.$, Franco Trevisani ${ }^{9}{ }^{\circledR}$ and Edoardo G. Giannini ${ }^{1, *(\mathbb{D}}$
}

check for updates

Citation: Plaz Torres, M.C.; Lai, Q.; Piscaglia, F.; Caturelli, E.; Cabibbo, G.; Biasini, E.; Pelizzaro, F.; Marra, F.; Trevisani, F.; Giannini, E.G. Treatment of Hepatocellular Carcinoma with Immune Checkpoint Inhibitors and Applicability of First-Line

Atezolizumab/Bevacizumab in a Real-Life Setting. J. Clin. Med. 2021, 10, 3201. https://doi.org/10.3390/ jcm10153201

Academic Editors: Pierluigi Toniutto and Hidekazu Suzuki

Received: 1 June 2021

Accepted: 19 July 2021

Published: 21 July 2021

Publisher's Note: MDPI stays neutral with regard to jurisdictional claims in published maps and institutional affiliations.

Copyright: (C) 2021 by the authors Licensee MDPI, Basel, Switzerland. This article is an open access article distributed under the terms and conditions of the Creative Commons Attribution (CC BY) license (https:/ / creativecommons.org/licenses/by/ $4.0 /)$.
1 Gastroenterology Unit, Department of Internal Medicine, IRCCS-Ospedale Policlinico San Martino, University of Genoa, 16132 Genoa, Italy; mariacorina.plaztorres@edu.unige.it

2 Hepatobiliary and Organ Transplantation Unit, Umberto I Polyclinic of Rome, Sapienza University of Rome, 00185 Rome, Italy; quirino.lai@uniroma1.it

3 Internal Medicine Unit, Department of Medical and Surgical Sciences, IRCCS Azienda Ospedaliero-Universitaria di Bologna, 40138 Bologna, Italy; fabio.piscaglia@unibo.it

4 Gastroenterology Unit, Belcolle Hospital, 01100 Viterbo, Italy; e.caturelli@tiscali.it

5 Gastroenterology and Hepatology Unit, Department of Health Promotion, Mother and Child Care, Internal Medicine and Medical Specialties (PROMISE), University of Palermo, 90133 Palermo, Italy; giuseppe.cabibbo@policlinico.pa.it

6 Infectious Diseases and Hepatology Unit, Azienda Ospedaliero-Universitaria di Parma, 43126 Parma, Italy; ebiasini@ao.pr.it

7 Gastroenterology Unit, Department of Surgery, Oncology and Gastroenterology, University of Padova, 35128 Padova, Italy; filippo.pelizzaro@unipd.it

8 Internal Medicine and Hepatology Unit, Department of Experimental and Clinical Medicine, University of Firenze, 50134 Firenze, Italy; fabio.marra@unifi.it

9 Medical Semeiotics Unit, Department of Medical and Surgical Sciences, IRCCS Azienda Ospedaliero-Universitaria di Bologna, 40138 Bologna, Italy; franco.trevisani@unibo.it * Correspondence: egiannini@unige.it; Tel.: +39-010-353-7950; Fax: +39-010-353-8638

\begin{abstract}
Immune checkpoint inhibitors (ICIs) are the new frontier for the treatment of advanced hepatocellular carcinoma (HCC). Since the first trial with tremelimumab, a cytotoxic T-lymphocyteassociated protein 4 inhibitor, increasing evidence has confirmed that these drugs can significantly extend the survival of patients with advanced hepatocellular carcinoma (HCC). As a matter of fact, the overall survival and objective response rates reported in patients with advanced HCC treated with ICIs are the highest ever reported in the second-line setting and, most recently, the combination of the anti-programmed death ligand protein- 1 atezolizumab with bevacizumab-an anti-vascular endothelial growth factor monoclonal antibody_demonstrated superiority to sorafenib in a Phase III randomized clinical trial. Therefore, this regimen has been approved in several countries as first-line treatment for advanced HCC and is soon expected to be widely used in clinical practice. However, despite the promising results of trials exploring ICIs alone or in combination with other agents, there are still some critical issues to deal with to optimize the prognosis of advanced HCC patients. For instance, the actual proportion of patients who are deemed eligible for ICIs in the real-life ranges from $10 \%$ to $20 \%$ in the first-line setting, and is even lower in the second-line scenario. Moreover, long-term data regarding the safety of ICIs in the population of patients with cirrhosis and impaired liver function are lacking. Lastly, no biomarkers have been identified to predict response, and thus to help clinicians to individually tailor treatment. This review aimed to summarize the state of the art immunotherapy in HCC and, by analyzing a large, multicenter cohort of Italian patients with HCC, to assess the potential applicability of the combination of atezolizumab/bevacizumab in the real-life setting.
\end{abstract}

Keywords: liver cancer; systemic treatment; immunotherapy; real-world; unresectable hepatocellular carcinoma 


\section{Introduction}

Hepatocellular carcinoma (HCC) is one of the leading causes of cancer-related mortality worldwide, with approximately 800,000 deaths per year and an estimated increase to more than 1 million deaths by 2030 [1]. HCC arises predominantly in the context of liver cirrhosis, but also can be diagnosed in a not negligible proportion of patients without cirrhosis suffering from non-alcoholic steato-hepatitis who carry additional metabolic and genetic risk factors [2-5]. In the past decades, the armamentarium for the systemic treatment of advanced HCC was limited to the anti-vascular endothelial growth factor (VEGFR), multi-target-tyrosine kinase inhibitor (TKI) sorafenib. This drug determined a significantthough modest-survival benefit in two Phase III trials and remained the sole first-line treatment option for about 10 years, during which neither an alternative drug nor effective second-line therapies became available for patients who progressed during-or were intolerant to-sorafenib [6,7]. As a fact, lenvatinib (a TKI targeting VEGFR) became an effective alternative to sorafenib as first-line therapy for HCC in 2018, while regorafenib, cabozantinib, and ramucirumab only recently have been approved in the second-line setting [8]. With the advent of second-line treatments, the survival of patients with advanced HCC has significantly improved, with a proportion (approximately 20\%) of patients reaching survival times of about 2 years with the sequential use of sorafenib-regorafenib [9]. These patients, however, belong to a small subgroup of patients who, maintaining an optimal liver function, are eligible for sequential treatment and tolerate the adverse effects of the anti-neoplastic agents [9].

In this scenario, immunotherapy has emerged as an additional promising approach potentially able to obtain even longer survival times. Research in this field is steadily increasing, also fueled by the positive results obtained in other cancer types and by the evidence of efficacy demonstrated in both first- and second-line settings [10-12]. The most recent Phase I/II trials have shown a clinically meaningful survival increase in the second-line setting for the programmed cell death protein 1 (PD-1) inhibitors nivolumab and pembrolizumab [12]. Hence, these agents have been granted accelerated conditional approval for sorafenib-experienced patients in the US, while the European Medicines Agency (EMA) maintains a more cautious attitude in approving these ICIs for the treatment of HCC. Indeed, subsequent Phase III trials testing nivolumab versus sorafenib as firstline treatment, and pembrolizumab versus placebo in second-line treatment, failed to meet their primary survival endpoints $[13,14]$. This notwithstanding, the results from trials testing the combination of immune checkpoint inhibitors (ICIs) with other agents, among which VEGFR-targeted therapies obtained very encouraging results, so that the combinations of pembrolizumab plus lenvatinib as well as atezolizumab (monoclonal antibody against PD-L1) plus bevacizumab (monoclonal antibody against VEGF) have both received breakthrough therapy designation from the US Food and Drug Administration (FDA). Actually, in a recent Phase III trial, the latter overperformed compared to sorafenib as first-line treatment of advanced HCC in terms of both overall (OS) and progression-free survival (PFS) [15]. Therefore, atezolizumab plus bevacizumab has been approved as the first-line treatment option for advanced HCC, thus becoming the standard of care for these patients.

Overall, the results from the trials testing ICIs alone or in combination, or combined with other agents, suggest that ICIs alone are not the best option for the treatment of HCC, while combined treatments are safe and highly effective. As such, immunotherapybased treatments will probably soon change the landscape of advanced HCC therapy. In this review, we summarize the state of the art immunotherapy in advanced HCC, with a particular focus on the combination of atezolizumab plus bevacizumab, by assessing in a large cohort of Italian patients with HCC the potential applicability of this regimen to the real-life setting. 


\section{Approved Treatments for HCC before the "Era" of Immune Checkpoint Inhibitors}

Until the approval of sorafenib in 2008, no systemic treatment was available for advanced HCC [6]. Sorafenib, an orally active multi-target TKI targeting different cell surface tyrosine kinases (e.g., VEGFR-1, -2 , and -3 and platelet-derived growth factor (PDGFR)- $\beta$ ), at the dose of $400 \mathrm{mg}$ twice daily, significantly improved OS in patients with HCC not amenable to surgery and locoregional procedures, who had well-preserved liver function (97\% Child-Pugh A) and Eastern Cooperative Oncology Group (ECOG) performance status (PS) $\leq 2$ [6]. The median OS was 10.7 months in the sorafenib group and 7.9 months in the placebo group $(p<0.001)$, whereas the median time to radiologic progression (TTP) was 5.5 months in the sorafenib arm versus 2.8 months in the placebo arm $(p<0.001)$. Of note, the median OS of patients with the Barcelona Clinic Liver Cancer (BCLC) staging system stage B HCC treated with sorafenib was 15-20 months, a finding confirmed by subsequent post-marketing studies $[16,17]$. In the following years, several drugs were tested against sorafenib in the first-line setting, failing to demonstrate superiority to this drug, so that sorafenib remained the sole effective systemic treatment available for HCC until 2018, when lenvatinib, an oral TKI with a biologic action similar to sorafenib, showed non-inferior OS as compared to sorafenib in the REFLECT trial, and was therefore approved as an alternative to this drug in the first-line setting [8]. Again, patients included in this trial belonged to a selected group of subjects with well-preserved liver function (Child-Pugh class A) and ECOG PS $\leq 1$, while those with extensive tumor burden ( $\geq 50 \%$ of the liver), bile duct invasion, or invasion of the main portal vein were excluded. Forest plots for OS revealed that lenvatinib was more effective than sorafenib in patients with baseline AFP $\geq 200 \mathrm{ng} / \mathrm{mL}$ (Hazard ratio (HR), 0.78; 95\% confidence interval (95\%CI), 0.63-0.98) and less effective in patients without macrovascular invasion/extrahepatic spread and those enrolled in the Western area. Secondary endpoints (PFS, TTP, objective response rate (ORR)) were significantly and remarkably better with lenvatinib, suggesting that these surrogate endpoints poorly predict OS in HCC patients treated with these drugs.

As far as the second-line setting is concerned, regorafenib, an oral TKI targeting VEGFR-2, VEGFR-3, TIE-2, PDGFR, fibroblast growth factor receptor (FGFR)-1, and the mutant oncogenic kinases KIT, RET, and B-RAF, was the first agent able to provide a significant survival benefit in patients with tumor progression on sorafenib [18]. Compared with placebo, regorafenib improved OS with a HR of $0.63(95 \% \mathrm{CI}, 0.50-0.79 ; p<0.0001)$. It has to be emphasized that this study enrolled patients who progressed on sorafenib but tolerated the drug ( $\geq 400 \mathrm{mg} /$ day for $\geq 20$ of last 28 days of treatment) and had Child-Pugh class A liver function. Median survival was 10.6 months $(95 \% \mathrm{CI}, 9.1-12.1)$ for the regorafenib group versus 7.8 months (95\%CI, 6.3-8.8) for the placebo group [18]. Interestingly, the treatment sequence of the sorafenib-regorafenib group was able to determine an OS of 26 months from the start of sorafenib treatment versus 19.2 months in the sorafenib-placebo group [18]. This survival time is comparable with that of patients with intermediate stage HCC undergoing trans-arterial chemo-embolization (TACE), suggesting that in a wellselected subgroup of patients the sequential treatment with TKIs may significantly improve prognosis as compared to the standard of care [9].

Other drugs that have shown efficacy in placebo-controlled trials and have consequently been approved as second-line treatment options for HCC are cabozantinib and ramucirumab [19]. Cabozantinib is an oral TKI targeting MET in addition to VEGFR2. The CELESTIAL trial was a global Phase III trial testing cabozantinib in patients with HCC progression on sorafenib [20]. It also included patients who had received up to two prior therapies for advanced-stage HCC. The study was stopped after a second interim analysis, which revealed a median OS of 10.2 months in the cabozantinib versus 8.0 months in the placebo group (HR, $0.76 ; 95 \%$ CI $0.63-0.92 ; p=0.0049$ ). Approximately $72 \%$ of patients had received only prior sorafenib treatment and, in this subpopulation, median OS was even longer, being 11.3 months in patients in the cabozantinib group versus 7.2 months in the placebo group (HR, 0.70; 95\% CI, 0.55-0.88) [20]. 
Ramucirumab is an anti-VEGFR2 monoclonal antibody, and its utility in subjects with advanced HCC emerged from the double-blind, Phase III REACH-2 trial comparing ramucirumab versus placebo as second-line treatment in patients progressing on sorafenib and with baseline AFP $\geq 400 \mathrm{ng} / \mathrm{mL}$ [19]. This study was designed on the basis of the results of the REACH trial that failed to demonstrate an OS advantage with ramucirumab as compared to the placebo, but in a post-hoc analysis showed a benefit of the drug —albeit small—in prolonging OS (8.5 months with ramucirumab versus 7.3 months with placebo (HR, 0.71; 95\% CI, 0.53-0.95; $p=0.0199)$ ) among patients with baseline $\mathrm{AFP} \geq 400 \mathrm{ng} / \mathrm{mL}$ [21]. Ramucirumab is therefore the first agent with a biomarker-driven use for patients with HCC progression on sorafenib [22].

In summary, sorafenib and lenvatinib are the TKIs that have long been in use for the front-line treatment of advanced HCC, providing a median extension of survival of about 3 months compared to the placebo. The survival benefit for patients eligible for secondline treatment with regorafenib/cabozantinib or ramucirumab, although significant, still remains modest. Hence, novel treatments targeting different tumorigenic pathways have been studied and others are still under investigation with the aim of further improving the outcomes of these patients. In this context, ICIs have gained excellent results.

\section{The Advent of Immune Checkpoint Inhibitors}

Despite the benefit in OS with sequential TKI treatment, the prognosis of patients with advanced HCC remains poor [9,23]. The reasons for this include, besides the sub-optimal tumoricidal activity of these drugs, the progression of the underlying liver disease, the advanced median age of this cohort of patients (approximately 70 years), and the presence of substantial comorbidities, which are very frequent in these subjects and, overall, make them a particularly vulnerable cohort [24].

In this context, ICIs have increasingly been investigated in the last years, with extremely encouraging results both in the first- and second-line setting, further boosting a rising number of clinical trials using ICIs alone or combined with other anti-tumoral drugs or with locoregional treatment. The rationale for the use of ICIs in HCC relies on the fact that HCC arises in a context of chronic inflammation and an altered tumor microenvironment, with the presence of tumor-infiltrating lymphocytes expressing PD1, which is a recognized key enabling factor beyond tumor cell-intrinsic molecular aberrations [25-27]. Moreover, the presence of PD1-expressing lymphocytes in HCC samples has been correlated with this outcome $[28,29]$. In this regard, Sia et al. have recently proposed a novel HCC classification based upon the tumor immune status: according to this classification, about $30 \%$ of HCCs could be categorized into an 'immune class', with high levels of immune cell infiltration, expression of PD-1 and/or PD-L1, activation of interferon- $\gamma$ signaling, and markers of cytolytic activity [30]. Within this class, two distinct subclasses have been identified: the 'active immune' and the 'exhausted immune' classes, characterized by markers of an adaptive T-cell response or of an exhausted immune response, respectively [30]. The latter subclass is the ideal target of immunotherapy. The in-depth description of the molecular mechanisms involved in the tumor microenvironment of HCC is beyond the aim of this article, but it is worth pointing out that interactions between cancer cell antigens and the antigen-presenting cells lead to a priming of T-cells and their eventual migration into the tumor microenvironment. Physiologically, the T-lymphocytes' recognition of neoplastic antigens is followed by a T-cell-mediated killing of cancer cells [31]. This process is finely modulated at a local and general level by several mechanisms including immune checkpoints, which play a pivotal role in such modulation, as they suppress T-cell activity to inhibit eventual over-activation of the immune system and maintain self-tolerance. Thus, immune checkpoints physiologically prevent hyperimmune responses leading to tissue damage. Malignancies exploit these molecular mechanisms (immune checkpoints) to escape from the immune system recognition. In other words, ICIs act as anti-neoplastic agents by inhibiting negative feedback pathways of the immune system that mediate immune escape. 
The most largely studied immune checkpoints are PD-1 and cytotoxic T-lymphocyteassociated protein 4 (CTLA-4). The pathological activation of PD-1 by its ligands, in particular PD-L1, expressed by cancer cells, can result in the immune escape of the tumor $[32,33]$. CTLA-4, which is mainly expressed on T-cells, regulates T-cell activity in physiological conditions, preventing an excess in T-cell responses and a hyperactivation of the immune response. Inversely, in pathological (neoplastic) conditions, CTLA-4 activation inhibits in the activation, proliferation, and production of tumor antigen-activated T-cells in the tumor microenvironment $[32,33]$. In the HCC tumor microenvironment, T-regulators (T-regs) express both CTLA-4 and PD-1 [28,32].

\section{Immune Checkpoint Inhibitors in HCC}

Tremelimumab, a CTLA-4-blocking monoclonal antibody, was the first ICI showing benefits in the treatment of HCC. This agent was tested in 2013 by Sangro et al. in a Phase II open-label trial that enrolled 21 patients with advanced HCC who were either sorafenibnaïve $(76.2 \%)$ or -experienced, and a significant proportion of them were classified as Child-Pugh class B (43\%) [10]. The positive results in terms of both safety and antitumor activity (partial response rate (PRR) 17.6\%; disease control rate (DCR) $76.4 \%$; TTP 6.48 months (95\%CI, 3.95-9.14)), were instrumental in stimulating the research in immune checkpoint blockade in both first- and second-line treatment of HCC. In the last years, the effects of ICIs in HCC have been tested alone or in combination with other ICIs or combined with agents targeting the VEGFR. Currently available immunotherapy-based regimens and those under Phase III clinical investigation are summarized in Figure 1.
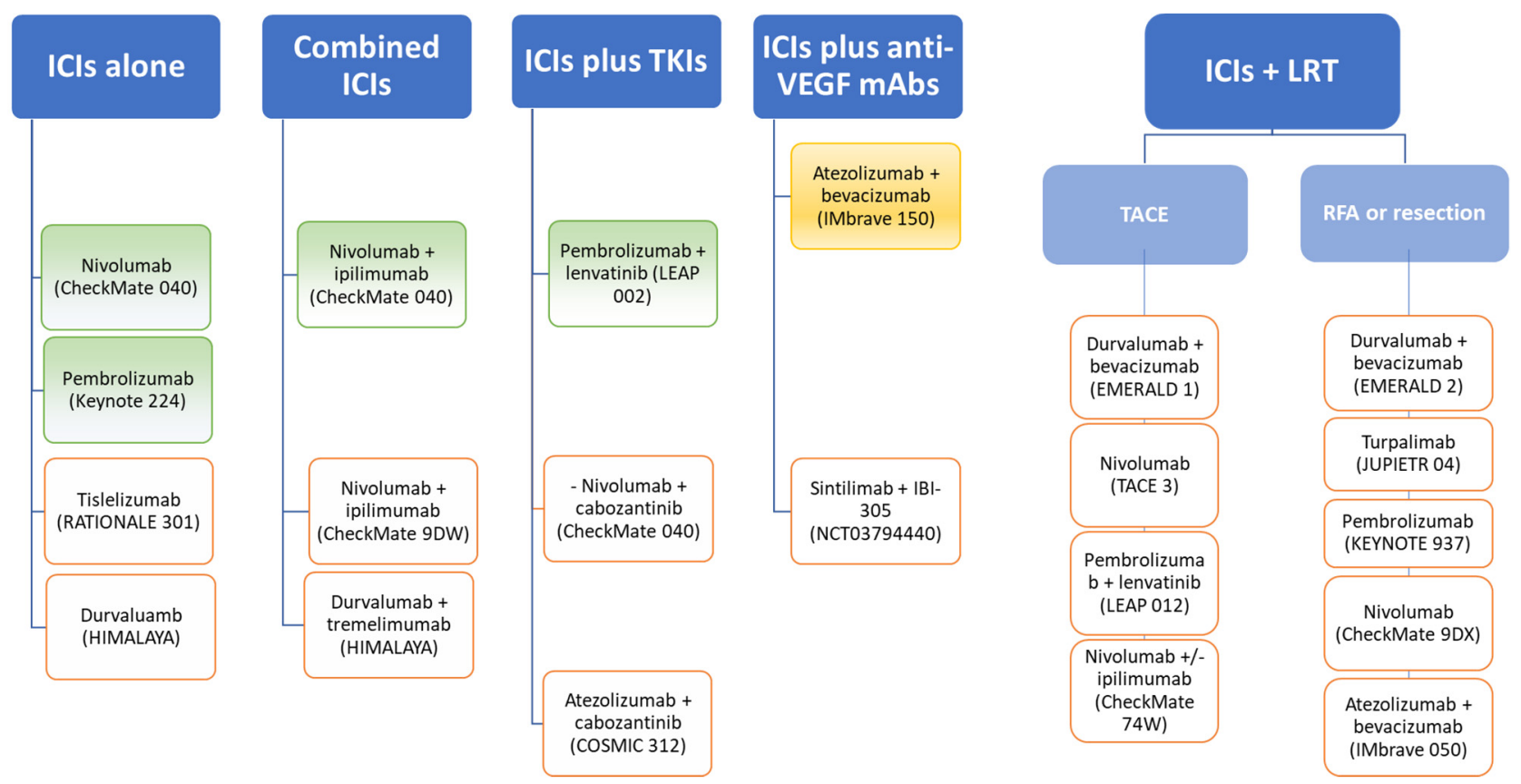

Figure 1. Possible HCC treatments with ICIs. Atezolizumab plus bevacizumab has been approved as a first-line treatment, whereas nivolumab with or without ipilimumab and pembrolizumab gained FDA approval as second-line treatments. Selected Phase III trials (orange squares) are testing ICIs alone or in combination or combined with other agents in the first and second-line setting, and in the adjuvant and neo-adjuvant setting as well.

\subsection{Immune Checkpoint Inhibitors in Monotherapy}

Following the encouraging results of the Phase II tremelimumab study, nivolumab, a monoclonal antibody targeting PD1, demonstrated a single-agent activity in the Phase $\mathrm{Ib} / \mathrm{II}$ open-label, non-comparative, Checkmate 040 trial [11]. The initial trial included 262 sorafenib-naïve and -experienced patients assigned to a dose-escalation (48 subjects) or to a dose-expansion (214 subjects) phase. In the dose-expansion phase, the investigator- 
assessed overall ORR was $20 \%$, with 3 complete responses (CR) and 39 partial responses (PR). Particularly, ORR was $22.5 \%$ for sorafenib-naive and $18.7 \%$ for sorafenib-experienced patients. Median OS was 29 months for sorafenib-naïve group and 15 months for the sorafenib-experienced group. The most impressive was the duration of response of 9.9 months amongst patients who had an objective response, which led the US FDA to grant accelerated approval to nivolumab as second-line therapy for patients with advanced-stage HCC previously treated with sorafenib [11]. In this subgroup, the ORR confirmed by blinded independent central review was $14.3 \%$ by Response Evaluation Criteria In Solid Tumors (RECIST) 1.1 and $18.2 \%$ by modified RECIST (mRECIST) criteria. Of note, the median duration of response was the longest ever seen in a second-line setting: 16.6 months [34,35]. However, the expectations raised by the results of this study were disappointed in a subsequent Phase III randomized trial (CheckMate-459) testing nivolumab versus sorafenib, as the anti-PD1 agent failed to demonstrate superiority as compared to the TKI [14]. Still, the study results confirmed clinically meaningful improvements in OS (16.4 versus 14.7 months), ORR (15\% for nivolumab versus $7 \%$ for sorafenib), and CR (14 versus 5 patients). Moreover, nivolumab demonstrated a favorable safety profile, consistent with previous reports and, of particular interest, the quality of life was better in the nivolumab treatment arm [14]. The long survival of the sorafenib arm (median OS of about 15 months) was an unexpected outcome that negatively impacted the study results and that probably reflects the improved tailored management of patients with advanced HCC in the last decades, as well as physicians' familiarity with the TKI.

Another ICI that has been tested with favorable outcomes in monotherapy for advanced HCC is pembrolizumab, a monoclonal antibody targeting PD-1. Promising results came from the Phase II trial KEYNOTE 224, which showed good responses (ORR 17\%, DCR 61\%) and a good safety profile of pembrolizumab in patients who were intolerant to, or progressed under, sorafenib [12]. These results prompted Finn et al. to conduct the KEYNOTE-240 trial enrolling 413 patients who failed sorafenib and who were randomized 2:1 to pembrolizumab or placebo [13]. The survival in the pembrolizumab arm was among the highest ever reached in the second-line setting, being approximately 14 months (95\%CI, 11.6-16.0) for pembrolizumab versus 10 months (95\%CI, 8.3-13.5) for placebo (HR, 0.781; 95\%CI, $0.611-0.998 ; p=0.0238)$. Nevertheless, even this study failed to reach statistical significance due to the long survival of the control arm, reflecting once more the advances in the clinical management of advanced HCC. The safety profile of the drug was good, confirming the positive results of the Phase II study and the previous experience with nivolumab.

Despite the apparently "negative" results of these studies, likely due to issues related to their design requesting an overwhelming superiority of the tested ICIs over sorafenib, several positive aspects capturing the attention of researchers and clinicians were the overall objective response to nivolumab and pembrolizumab in $15-20 \%$ of cases, the durable antitumor responses, and the long-term OS in responding patients. Based on these peculiar results, the FDA granted conditional approval for these ICIs in the second-line setting.

Currently, results from the ongoing Phase III non-inferiority trial testing tislelizumab, a monoclonal antibody targeting PD-1, versus sorafenib (RATIONALE-301 trial) and those of the Phase III HIMALAYA study, testing durvalumab - an anti-PD-L1 monoclonal antibody-alone or in combination with tremelimumab versus sorafenib, are eagerly awaited [36].

As far as the safety profile of ICIs is concerned, the results of the pilot study by Sangro et al. on tremelimumab and those of the CheckMate and Keynote trials showed reassuring safety profiles for these agents, coherent with previous reports testing the use of these drugs in other cancer types [10-12,37]. As compared with the standard of care (i.e., sorafenib and lenvatinib), ICIs are generally better tolerated and have comparable or even lower rates of toxicity. The pathophysiology of adverse events (AEs) occurring during immunotherapy is related to their mechanism of action as the inhibition of physiological immune checkpoints may trigger immune-related AEs (irAEs) targeting the skin, gut, thyroid, adrenal glands, lung, and the liver itself, which may be a particularly worrisome complication in 
a population with an already impaired liver function [38,39]. Most frequent any grade AEs in patients treated with ICIs for other cancer types are skin AEs (rash and pruritus), colitis, hyper- or hypothyroidism, hepatitis, and pneumonitis. Skin AEs occur in about $13-35 \%$ of cases, being grade $>3$ only in a minority of cases $(<3 \%)[38,40]$. Grade 1 and 2 skin AEs are usually easily managed with emollients, oral anti-histamines, and topical steroids, whereas grade $\geq 3$ reactions require oral corticosteroids administration and the discontinuation of the immunotherapy until the skin AE has reverted to grade 1 [38]. Thyroid dysfunction has been reported in a variable proportion of cases $(5-20 \%)$, but these events are rarely severe and rarely require treatment discontinuation or hormonal replacement treatment or corticosteroids administration [38]. The frequency of colitis ranges from $2 \%$ to $22 \%$ [38,40], being more frequent and severe in patients treated with anti-CTLA4 agents $[38,40]$. Again, the incidence of high-grade colitis is very low, being around 1-2\% [40]. Patients with non-severe diarrhea should be treated with anti-diarrheal, fluid replacement, and electrolytes; conversely, patients with grade $\geq 3$ diarrhea or persistent grade 2 diarrhea should discontinue ICIs and receive intravenous (i.v.) corticosteroids. In case of lack of response to corticosteroids, infliximab should be prescribed [38]. Pneumonitis occurs in $2-4 \%$ of patients, with grade $\geq 3$ events representing only $1 \%$ to $2 \%$ of cases $[38,40]$, and the frequency of fatal pneumonitis and that of treatment discontinuation (due to this $\mathrm{AE}$ ) are extremely low $(0.2 \%$ and $0.2-4 \%$, respectively) [38]. In the case of documented or high suspicion of immune-related pneumonitis, immunosuppressive treatment should be started immediately. In grade 1 to 2 pneumonitis, treatment consists of oral steroids (prednisone $1 \mathrm{mg} / \mathrm{kg}$ daily), whilst patients with grade 3 to 4 pneumonitis should be hospitalized and treatment should consist of high-dose i.v. corticosteroids. In these severe cases, immunotherapy should be permanently discontinued. With regards to the occurrence of treatment-related hepatitis, which occurs in a proportion of $5 \%$ to $10 \%$ of patients (among which 1-2\% are grade 3) [38,40], in the presence of grade $\leq 2$ transaminases elevation, checkpoint inhibitor therapy should be withheld and transaminases and bilirubin should be measured twice weekly. Persistent grade 2 elevation lasting longer than 2 weeks, after having ruled out other causes, should be treated with corticosteroids at a dose of $1 \mathrm{mg} / \mathrm{kg} /$ day (methyl)prednisolone or equivalent. Upon improvement, re-challenge with ICIs may be attempted after corticosteroid tapering. In the absence of improvement despite the initiation of corticosteroids, the dose should be increased to $2 \mathrm{mg} / \mathrm{kg} /$ day of (methyl)prednisolone or equivalent and checkpoint inhibitor therapy should permanently be discontinued [38]. In the instance of grade 3 or 4 transaminase or total bilirubin elevation, checkpoint inhibitor therapy should be permanently discontinued, and corticosteroids started at $1-2 \mathrm{mg} / \mathrm{kg} /$ day (methyl)prednisolone or equivalent. If the absence of response to corticosteroids within 2-3 days, mycophenolate mofetil should be added at $1000 \mathrm{mg}$ twice daily. If no improvement is seen, liver biopsy should be considered. However, ICI-related hepatitis usually resolves within 4-6 weeks with appropriate treatment; therefore, if no improvement is detected in this time frame, other contributory causes should be reconsidered and the initial diagnostic work-up should be repeated.

Overall, the available evidence suggests that, although common, irAEs can be easily managed in most cases by delaying the subsequent scheduled administrations, and with the administration of corticosteroids in severe cases [39]. In HCC studies, approximately $90-98 \%$ of patients experienced any AE during treatment, with up to $50 \%$ of them being grade 3 or higher [10-14]. However, similar rates of AEs have been recorded in randomized controlled trials in the respective placebo arms as well [13]. With regards to treatment-related AEs, grade $\geq 3$ AEs have been reported in approximately $20 \%$ of cases for nivolumab and pembrolizumab monotherapy [13,14]; among them, the most frequent $\mathrm{AE}$ in the Keynote- 240 and CheckMate-040 studies was aminotransferase increase (about $4-5 \%$ and $6-10 \%$, respectively) $[11,13]$. This event is of particular concern in patients with cirrhosis due to the potential deterioration of liver function and to the peculiar risk of corticosteroid-related AEs in these subjects. However, current data show that ICIs are safe in well-selected cohorts of patients with cirrhosis and preserved liver 
function (Child-Pugh class A), with no safety alerts as compared with patients without cirrhosis treated with ICIs for other cancer types $[9,41]$. The available evidence thus suggests that cirrhotic patients with HCC should not be at increased risk of liver irAEs, but close monitoring of liver function tests should be performed in cirrhotic patients treated with ICIs. Treatment-related serious AEs such as pneumonitis and colitis occurred in a minority of patients $(<1 \%)$, as reported in the literature for immunotherapy in other cancer types [11,12]. Definite data on the safety and tolerability of ICIs in Child-Pugh class B patients, which represent a significant proportion of advanced HCC patients, are lacking. However, those from the CheckMate-040 trial are reassuring, since only 4 out of 49 patients with Child-Pugh class B reported treatment-related hepatic events, and only 2 of them needed treatment discontinuation [38]. Moreover, similar results regarding the safety of nivolumab and pembrolizumab in patients with Child-Pugh class B have been observed by Scheiner et al. in a real-life cohort of HCC patients [41]. Taken together, the available evidence suggests the safety profile of ICIs in the HCC population is good in selected cases with well-preserved liver function and that ICIs may be safely administered in Child-Pugh class B patients as well.

\subsection{Dual Immune Chechpoint Blockade}

Based on the hypothesis that anti-PD-1 and anti-CTLA4 agents may have a synergistic effect by inhibiting two different steps of the immune checkpoint system, combinations of anti-PD1 and anti-CTLA4 are underway. A Phase III trial with dual treatment with nivolumab plus ipilimumab, a CTLA-4 monoclonal antibody, in the first-line setting (CheckMate 9DW, NCT04039607) is underway. This trial was supported by the positive results observed in the cohort 4 (nivolumab plus ipilimumab) of the Checkmate-040 trial in the second-line setting [42]. In this study, patients were randomized 1:1:1 to either nivolumab $1 \mathrm{mg} / \mathrm{kg}$ plus ipilimumab $3 \mathrm{mg} / \mathrm{kg}$, administered every 3 weeks (4 doses), followed by nivolumab $240 \mathrm{mg}$ every 2 weeks (arm A); nivolumab $3 \mathrm{mg} / \mathrm{kg}$ plus ipilimumab $1 \mathrm{mg} / \mathrm{kg}$, administered every 3 weeks (4 doses), followed by nivolumab $240 \mathrm{mg}$ every 2 weeks (arm B); or nivolumab $3 \mathrm{mg} / \mathrm{kg}$ every 2 weeks plus ipilimumab $1 \mathrm{mg} / \mathrm{kg}$ every 6 weeks (arm C). Treatment combination had manageable safety, promising ORR, and durable responses. The arm A regimen showed the greatest benefits in terms of ORR (32\% versus $27 \%$ and $29 \%$ in arms B and C, respectively) and OS (22.8 months (95\%CI, 9.4-not reached) in arm A versus 12.5 months (95\%CI, 7.6-16.4) in arm B and 12.7 months in arm C (95\%CI, 7.4-33.0) [43]. Any grade treatment-related AE occurred in $94 \%$ of cases in arm A, 71\% in arm B, and 79\% of cases in arm C. Among them, 53\% of patients in arm A, 29\% of patients in arm B, and 31\% of patients in arm C had grade 3 or 4 treatment-related AEs. Arm A also had higher rates of irAEs and irAEs leading to treatment discontinuation (18\%), as compared with arms B and C (6\% and $4 \%$, respectively). Consequently, in arm A, 16\% of patients stopped treatment: $6 \%$ of them due to treatmentrelated hepatitis, $6 \%$ due to pneumonitis, and $4 \%$ due to diarrhea/colitis [43]. However, most cases of patients presenting AEs continued treatment and the AEs resolved with standard management, while only 1 treatment-related death due to pneumonitis was reported (0.6\%) [43]. Importantly, among patients who were re-challenged with nivolumab or ipilimumab after experiencing an irAE in any category, no patients experienced an event recurrence after the re-challenge [43]. Considering the outstanding OS and ORR obtained in arm A, these results suggest that nivolumab plus ipilimumab may provide improved efficacy in terms of ORR, and, potentially, of survival with an acceptable safety profile. Based on this evidence, this dual treatment received accelerated approval in the US as second-line treatment for HCC.

In the first-line setting, a Phase III trial (HIMALAYA) is testing the PD-L1 inhibitor durvalumab alone and in combination with tremelimumab, compared with sorafenib. This study was designed on the basis of the findings from a Phase I/II, randomized, open-label study that included patients progressing under, intolerant to, or refusing sorafenib [44]. Patients were randomized 1:2 to different tremelimumab plus durvalumab combinations, 
and safety was the primary endpoint. Patients assigned to the high-dose tremelimumab arm (i.e., tremelimumab $300 \mathrm{mg}$ plus durvalumab $1500 \mathrm{mg} 1$ dose followed by durvalumab every 4 weeks) had the highest confirmed ORR (duration of response not reached) and longest OS (18.7 months (10.8-not reached)) [44]. Grade 3 or 4 treatment-related AEs rates were comparable to those occurring in the nivolumab plus ipilimumab trials, being $35 \%$ in the high-dose (300 $\mathrm{mg}$ ) tremelimumab arm and $25 \%$ in the low-dose $(75 \mathrm{mg})$ tremelimumab arm. Discontinuation of the study drug due to AEs was $10.8 \%$ and $6 \%$ in the high- and low-dose arm, respectively, but no deaths were attributed to treatment.

In summary, dual checkpoint blockade may improve OS in HCC patients, but consistent evidence is still scarce. As might have been expected, the trials testing ICIs in dual treatment reported higher rates of AEs in comparison with ICIs used in monotherapy, but in most cases, the safety profile was consistent in presentation and management with that of monotherapy. Taking into consideration the poor prognosis of patients with advanced HCC, the benefit/risk ratio may still favor the dual treatment strategy. Current trials with dual checkpoint blockade are reported in Table 1.

Table 1. Ongoing clinical trials with immune checkpoint inhibitors, alone or in combination with other agents, in HCC.

\begin{tabular}{|c|c|c|c|c|c|c|c|c|}
\hline $\begin{array}{l}\text { Trial } \\
\text { Name }\end{array}$ & Phase & $\begin{array}{l}\text { Line of } \\
\text { Treatment }\end{array}$ & Design & $\begin{array}{l}\text { Patients } \\
\text { Enrolled }\end{array}$ & Endpoints & ClinicalTrial.gov & Company & Status \\
\hline GO30140 & I & First-line & $\begin{array}{c}\text { Atezolizumab + } \\
\text { Bevacizumab (arm A) } \\
\text { Atezolizumab + } \\
\text { Bevacizumab (arm F1) } \\
\text { Atezolizumab (arm F2) }\end{array}$ & 430 & $\begin{array}{c}\text { Safety, efficacy, } \\
\text { pharmacokinetics }\end{array}$ & NCT02715531 & $\begin{array}{l}\text { Hoffmann-La } \\
\text { Roche }\end{array}$ & $\begin{array}{l}\text { Active, not } \\
\text { recruiting }\end{array}$ \\
\hline- & I & No restriction & $\begin{array}{c}\text { Ramucirumab + } \\
\text { MEDI4736 [HCC] (arm C) }\end{array}$ & 114 & DLTs & NCT02572687 & $\begin{array}{c}\text { Eli Lilly \& } \\
\text { Co/Astra Zeneca }\end{array}$ & $\begin{array}{l}\text { Active, not } \\
\text { recruiting }\end{array}$ \\
\hline NUANCE & I & Second-line & $\begin{array}{l}\text { Nivolumab }+ \\
\text { bevacizumab }\end{array}$ & 1 & $\begin{array}{l}\text { Safety and } \\
\text { tolerability }\end{array}$ & NCT03382886 & University of Utah & Terminated \\
\hline- & I & Neo-adjuvant & $\begin{array}{l}\text { Nivolumab + } \\
\text { cabozantinib }\end{array}$ & 15 & $\begin{array}{l}\text { Safety and } \\
\text { tolerability }\end{array}$ & NCT 03299946 & $\begin{array}{l}\text { Sidney Kimmel } \\
\text { Compehensive } \\
\text { Cancer Center at } \\
\text { John Hopkins }\end{array}$ & $\begin{array}{l}\text { Active, not } \\
\text { recruiting }\end{array}$ \\
\hline- & $\mathrm{Ib}$ & First-line & $\begin{array}{c}\text { Regorafenib + } \\
\text { pembrolizumab }\end{array}$ & 57 & $\begin{array}{l}\text { Safety and } \\
\text { tolerability }\end{array}$ & NCT03347292 & Bayer & Recruiting \\
\hline- & $\mathrm{Ib}$ & First-line & $\begin{array}{c}\text { Pembrolizumab } \\
\text { lenvatinib }\end{array}$ & 104 & $\begin{array}{l}\text { Safety and } \\
\text { tolerability }\end{array}$ & NCT 03006926 & Eisai Co., Ltd. & $\begin{array}{l}\text { Active, not } \\
\text { recruiting }\end{array}$ \\
\hline- & $\mathrm{Ib}$ & First-line & Nivolumab + lenvatinib & 30 & $\begin{array}{l}\text { Safety and } \\
\text { tolerability }\end{array}$ & NCT03418922 & Eisai Co., Ltd. & $\begin{array}{l}\text { Active, not } \\
\text { recruiting }\end{array}$ \\
\hline- & $\mathrm{Ib}$ & Second-line & Sintilimab + IBI305 & 47 & AEs/ORR & NCT04401813 & $\begin{array}{l}\text { Innovent Biologics } \\
\text { (Suzhou) Co., Ltd. }\end{array}$ & Recruiting \\
\hline- & I/IIa & First-line & $\begin{array}{c}\text { Nivolumab + } \\
\text { Pexastimogene } \\
\text { devacirepvec }\end{array}$ & & $\begin{array}{l}\text { Safety and } \\
\text { tolerability }\end{array}$ & NCT03071094 & Transgene & $\begin{array}{l}\text { Active, not } \\
\text { recruiting }\end{array}$ \\
\hline $\begin{array}{l}\text { CheckMate } \\
040\end{array}$ & $\mathrm{I} / \mathrm{II}$ & Second-line & $\begin{array}{l}\text { Cohort 4: Nivolumab + } \\
\text { ipilimumab } \\
\text { Cohort 6: Nivolumab + } \\
\text { cabozantinib }\end{array}$ & 148 & $\begin{array}{l}\text { Safety and } \\
\text { tolerability }\end{array}$ & NCT01658878 & $\begin{array}{l}\text { Bristol-Myers } \\
\text { Squibb/Ono } \\
\text { Pharmaceutical } \\
\text { Co., Ltd. }\end{array}$ & $\begin{array}{l}\text { Active, not } \\
\text { recruiting }\end{array}$ \\
\hline- & $\mathrm{I} / \mathrm{II}$ & Second-line & SHR-1210 + apatinib & 60 & OS & NCT02942329 & $\begin{array}{c}\text { The Affiliated } \\
\text { Hospital of the } \\
\text { Chinese Academy } \\
\text { of Military Medical } \\
\text { Sciences }\end{array}$ & Unknown \\
\hline- & $\mathrm{Ib} / \mathrm{II}$ & First-line & $\begin{array}{c}\text { Pembrolizumab + } \\
\text { talimogene laherarepvec }\end{array}$ & 244 & ORR/DLTs & NCT02509507 & Amgen & Recruiting \\
\hline- & II & $\begin{array}{l}\text { First-line and } \\
\text { Second-line }\end{array}$ & $\begin{array}{c}\text { Durvalumab + } \\
\text { tremelimmumab } \\
\text { [regimen 1] (arm A) } \\
\text { Durvalumab (arm B) } \\
\text { Tremelimumab (arm C) } \\
\text { Durvalumab + } \\
\text { tremelimumab } \\
\text { [regimen 2] (arm D) } \\
\text { Durvalumab + } \\
\text { bevacizumab (arm E) }\end{array}$ & 545 & $\begin{array}{l}\text { Safety and } \\
\text { tolerability }\end{array}$ & NCT02519348 & MedImmune, LLC & $\begin{array}{l}\text { Active, not } \\
\text { recruiting }\end{array}$ \\
\hline
\end{tabular}


Table 1. Cont.

\begin{tabular}{|c|c|c|c|c|c|c|c|c|}
\hline RESCUE & II & Second-line & SHR-1210 + apatinib & 190 & ORR & NCT03463876 & $\begin{array}{l}\text { Jiangsu HengRui } \\
\text { Medicine Co., Ltd. }\end{array}$ & $\begin{array}{l}\text { Active, not } \\
\text { recruiting }\end{array}$ \\
\hline- & II & $\begin{array}{l}\text { First- } \\
\text { line/Second- } \\
\text { line }\end{array}$ & $\begin{array}{c}\text { SHR1210 + apatinib } \\
(\text { arm A) }\end{array}$ & 152 & $\begin{array}{l}\text { Safety and } \\
\text { tolerability }\end{array}$ & NCT03092895 & $\begin{array}{l}\text { Jiangsu HengRui } \\
\text { Medicine Co., Ltd. }\end{array}$ & Unknown \\
\hline IMMUNIB & II & First-line & Nivolumab + lenvatinib & 50 & $\begin{array}{l}\text { ORR/safety and } \\
\text { tolerability }\end{array}$ & NCT03841201 & $\begin{array}{l}\text { Institut fur } \\
\text { Klinische } \\
\text { Krebsforschung } \\
\text { IKF GmbH }\end{array}$ & Recruiting \\
\hline- & II & $\begin{array}{l}\text { First- } \\
\text { line/Second- } \\
\text { line }\end{array}$ & $\begin{array}{l}\text { Nivolumab + Ipilimumab } \\
\text { vs. nivolumab }\end{array}$ & & $\begin{array}{l}\text { Safety and } \\
\text { tolerability }\end{array}$ & NCT03222076 & $\begin{array}{l}\text { MD Anderson } \\
\text { Cancer Center }\end{array}$ & $\begin{array}{l}\text { Active, not } \\
\text { recruiting }\end{array}$ \\
\hline- & II/III & First-line & Sintilimab + IBI305 & 566 & OS/PFS & NCT03794440 & $\begin{array}{l}\text { Innovent Biologics } \\
\text { (Suzhou) Co., Ltd. }\end{array}$ & Recruiting \\
\hline IMbrave150 & III & First-line & $\begin{array}{c}\text { Atezolizumab + } \\
\text { bevacizumab (arm A) } \\
\text { Sorafenib (arm B) }\end{array}$ & 480 & OS/PFS & NCT03434379 & $\begin{array}{l}\text { Hoffmann-La } \\
\text { Roche }\end{array}$ & $\begin{array}{l}\text { Active, not } \\
\text { recruiting }\end{array}$ \\
\hline $\begin{array}{l}\text { COSMIC- } \\
312\end{array}$ & III & First-line & $\begin{array}{c}\text { Cabozantinib + } \\
\text { atezolizumab }(\operatorname{arm} \mathrm{A}) \\
\text { Sorafenib }(\operatorname{arm~B}) \\
\text { Cabozantinib }(\operatorname{arm} \mathrm{C})\end{array}$ & 740 & $\mathrm{PFS} / \mathrm{OS}$ & NCT03755791 & Exelixis & Recruiting \\
\hline LEAP-002 & III & First-line & $\begin{array}{c}\text { Pembrolizumab }+ \\
\text { Lenvatinib vs. placebo }+ \\
\text { lenvatinib }\end{array}$ & 750 & PFS/OS & NCT03713593 & $\begin{array}{l}\text { Merck Sharp \& } \\
\text { Dohme Corp. }\end{array}$ & $\begin{array}{l}\text { Active, not } \\
\text { recruiting }\end{array}$ \\
\hline- & III & First-line & $\begin{array}{l}\text { SHR-1210 + FOLFOX4 vs. } \\
\text { sorafenib or FOLFOX4 }\end{array}$ & 448 & OS & NCT03605706 & $\begin{array}{l}\text { Jiangsu HengRui } \\
\text { Medicine Co., Ltd. }\end{array}$ & Recruiting \\
\hline HIMALAYA & III & First-line & $\begin{array}{c}\text { Durvalumab (arm A) } \\
\text { Durvalumab }+ \\
\text { tremelimumab } \\
\text { [regimen 1] (arm B) } \\
\text { Durvalumab + } \\
\text { tremelimumab } \\
\text { [regimen 2] (arm C) } \\
\text { Sorafenib (arm D) }\end{array}$ & 1310 & OS & NCT03298451 & AstraZeneca & $\begin{array}{l}\text { Active, not } \\
\text { recruiting }\end{array}$ \\
\hline- & III & First-line & $\begin{array}{l}\text { CS1003 + lenvatinib vs. } \\
\text { placebo + lenvatinib }\end{array}$ & 525 & $\mathrm{PFS} / \mathrm{OS}$ & NCT04194775 & $\begin{array}{c}\text { CStone } \\
\text { Pharmaceuticals }\end{array}$ & Recruiting \\
\hline
\end{tabular}

HCC, hepatocellular carcinoma; DLTs, dose-limiting toxicities; AEs, adverse events; OS, overall survival; PFS progression-free survival; ORR, overall response rate.

\subsection{Immune Checkpoint Inhibitors Combined with Tyrosine Kinase Inhibitors}

In addition to its well-known stimulating effect on angiogenesis, VEGF can promote immune evasion by directly and indirectly inhibiting infiltration and function of cytotoxic T-lymphocytes and increasing PD-1 expression on intra-tumoral CD8+ T-cells. In other words, the VEGF pathway is involved in the recruitment of immunosuppressive T-reg cells into the tumor. Thus, VEGF inhibition through TKIs or VEGFR-directed monoclonal antibodies might increase local antitumor immunity and favorably modify the immunosuppressive tumor microenvironment, thus enhancing the effects of ICIs [45]. On this basis, several Phase I/II trials testing combinations of anti-PD1/PD-L1 with anti-VEGFRs were undertaken and have already shown promising results in this research field, paving the way for Phase III trials that are currently in progress (Table 1) [46].

Among these studies, one trial tested the combination of nivolumab plus cabozantinib, with or without ipilimumab, reporting preliminary clinically meaningful responses [47]. As of today, the results of this study, which included 71 patients randomized to either nivolumab plus cabozantinib $(n=36)$ or nivolumab plus ipilimumab and cabozantinib $(n=35)$, are only partially available, and show that investigator-assessed ORR was comparable with that of nivolumab alone for the dual treatment arm (17\%, 6 patients with PR) but reached $26 \%$ (9 patients with PR) in the triple treatment arm. The diseased control rate was good and similar in the two groups, being $81 \%$ for the dual treatment arm and $83 \%$ for the triple treatment arm. It is noteworthy that the median OS was not reached in either arm [47]. With regards to safety, grade 3 or 4 treatment-related AEs were observed in $42 \%$ of cases in the dual treatment arm and in $71 \%$ of cases in the triple treatment arm, leading 
to treatment discontinuation in $3 \%$ and $20 \%$ of patients, respectively. However, no new safety signals were observed in either arm. Based on these promising findings, complete and updated results of this trial are eagerly awaited.

Another combination that is currently under investigation in patients with advanced HCC is that of pembrolizumab plus lenvatinib, which, in a Phase Ib study, showed good results with a median OS of 22 months and a $46 \%$ confirmed ORR [48]. Hence, this combination has been granted a breakthrough therapy designation by the FDA for advanced HCC patients who are not amenable to locoregional treatment, and it is currently being tested in a Phase III, international, multicenter clinical study (LEAP-002).

\subsection{Immune Checkpoint Inhibitors Combined with Anti-VEGFR Agents}

Recently, Finn et al. tested the combination of atezolizumab, a monoclonal antibody targeting PD-L1, plus bevacizumab, an anti-VEGF monoclonal antibody, as a front-line treatment of advanced HCC. The trial (IMbrave-150) showed a clear superiority of the dual therapy over sorafenib [15]. The intention-to-treat population included 336 patients in the atezolizumab plus bevacizumab group and 165 patients in the sorafenib group. At the time of the primary interim analysis, the HR for death with atezolizumab plus bevacizumab as compared with sorafenib was 0.58 (95\%CI, $0.42-0.79 ; p<0.001)$. The reported 12-month OS was 67.2\% (95\%CI, 61.3-73.1) with atezolizumab plus bevacizumab versus $54.6 \%$ (95\%CI, 45.2-64.0) with sorafenib. Median PFS was 6.8 months (95\%CI, 5.7 to 8.3) and 4.3 months $(95 \% \mathrm{CI}, 4.0-5.6)$ in the respective groups (HR for disease progression or death: $0.59 ; 95 \% C I, 0.47-0.76 ; p<0.001$ ) [15]. Hypertension, proteinuria, and fatigue were the top three treatment-related AEs in the combination arm. Upper gastrointestinal bleeding, a known AE of bevacizumab and a main concern in patients with cirrhosis, occurred in $7 \%$ of patients in this group, which is well within the range of previous studies evaluating the use of bevacizumab in HCC $[49,50]$. Esophageal varices hemorrhage occurred in $2.4 \%$ of cases, but only $1.8 \%$ were grade $\geq 3$ and less than $1 \%$ of cases needed treatment discontinuation. Of note, in this study, causality was reported only in $<1 \%$ of patients [15]. In this respect, it is important to emphasize that patients intended to receive the combination of atezolizumab plus bevacizumab had undergone endoscopic variceal screening, as per the study protocol. Given the increased bleeding risk associated with bevacizumab, patients with gastro-esophageal varices at risk of bleeding received adequate prophylactic treatment, as must be done in standard care of cirrhotic patients with esophageal varices [51,52]. Increases in aminotransferases and pruritus were other common AEs attributable to atezolizumab but, again, only a few patients ( $0.6 \%$ of cases) needed to stop treatment and developed immune-mediated liver damage. The proportion of patients who discontinued any treatment component because of AEs was $15.5 \%$ in the atezolizumab plus bevacizumab group ( $7 \%$ discontinued both components) and $10.3 \%$ in the sorafenib group [15]. Overall, AEs leading to dose modification or interruption occurred in $49.5 \%$ of patients who received atezolizumab plus bevacizumab and in $60.9 \%$ of those who received sorafenib. Therefore, this study provided the first and strong-evidence of the benefit provided by combining an ICI and a VEGFR inhibitor for patients with advanced HCC, and its superiority over sorafenib has undoubtedly already changed the standard of care for these patients, where it has substituted sorafenib as first-line treatment in most cases. Nevertheless, as only patients with Child-Pugh class A were included in this study, which is standard practice in HCC trials, so no consistent data are available regarding efficacy and safety of this combination in patients with a greater impairment in liver function. To date, only one study has reported the outcomes for four Child-Pugh class B patients treated with atezolizumab plus bevacizumab in a Japanese cohort of patients [53]. Among these patients, all patients could be treated without the development of severe AEs until tumor progression and efficacy was comparable to that of Child-Pugh class A patients. These results are undoubtedly important, but further research in larger cohorts of patients is needed before a recommendation can be made for the use of this immunotherapy in patients with Child-Pugh class B liver function. However, we could argue that well selected patients 
with Child-Pugh class B7 liver function may be treated safely with atezolizumab plus bevacizumab but close monitoring of biochemistry and close clinical monitoring should be performed and patients should be informed that the benefit of this treatment in the Child-Pugh class B population still has to be determined.

The role of sorafenib and that of lenvatinib and, more in general, the treatment algorithms for the systemic treatment of HCC, will soon need to be reviewed in order to be optimized. Whether TKIs are going to be part of the second-line treatment alternatives, alone or in combination with other agents, is still unknown and extensive research is ongoing to try to adequately frame treatment sequences.

\subsection{Immune Checkpoint Inhibitors Combined with Locoregional Treatments for HCC}

To date, no systemic treatment tested in combination with locoregional treatments for HCC has demonstrated benefit in terms of OS. Conversely, ICIs might revolutionize the therapeutic panorama of early and intermediate stage HCC, thus achieving a role not only in the setting of palliative treatment, but also in the curative one. The rationale for their use in combination with radiofrequency ablation (RFA) and TACE relies on the fact that ablative and intra-arterial techniques indirectly induce a peripheral immune response that can enhance the effect of ICIs [54,55] (Figure 2). Namely, the RFA- and TACE-induced necrosis of tumor cells favors the release of tumor antigens and the activation of immune-mediated death of tumor cells, which, in turn, stimulate a peripheral systemic immune response that can potentially be amplified by immune checkpoint blockade [56-61]. Arayu et al. showed that alpha-fetoprotein-specific CD4+ T-cell responses to three immune-dominant epitopes in HCC patients were significantly expanded during and after embolization $(p<0.002)$. Specifically, the development of alpha-fetoprotein-specific CD4+ T-cells after treatment was significantly associated with the induction of $>50 \%$ necrosis of tumor and an improved clinical outcome $(p<0.007)$ [57]. Similarly, Mizokushiet al, evaluating T-cell responses in patients with HCC undergoing RFA, observed immune responses to antigens for which no T-cell response was detected before RFA [60]. Interestingly, the number of tumor-specific T-cells after RFA correlated with the prevention of HCC recurrence in patients treated with curative intent [60]. Moreover, RFA ablation not only provides activating signals for T-cell responses against HCC, but also augments the pool of circulating natural killer (NK) lymphocytes and enhances preferential expression of NK cells' activating receptors and NK cells' cytotoxicity, and all these effects are seen as soon as one week after treatment [61].

Although very limited data exist in patients with very early or early HCC (BCLC 0 or BCLC A stage) and intermediate HCC (BCLC B stage) treated with ICIs in the adjuvant and neo-adjuvant setting, preliminary data are promising. With regards to the neo-adjuvant setting, a recent pilot randomized, Phase II trial showed that dual treatment with nivolumab plus ipilimumab prior to surgery leads to a complete pathological response rate in $33.3 \%$ of cases [62]. An increase in T-cell infiltration and upregulation of cytotoxic and effector memory cell markers in tissue after treatment was also seen, as compared with before treatment [62]. Two other small studies investigated tumor-specific immune responses after combined TACE and RFA treatment, or after each individual treatment, confirming that ablative therapies induce tumor-specific T-cell responses in individual patients upon ablative therapies $[59,63]$.

Combined ICIs plus TACE or RFA are not the only treatments under investigation, as some reports regarding the combination of trans-arterial $\mathrm{Y}^{90}$-radioembolization (TARE) and immune checkpoint blockade have been presented at recent oncological meetings with promising results. In particular, Tai et al. reported the results of a Phase II, open-label, single-center, non-randomized trial regarding the effects of a combined therapy with TARE and nivolumab for advanced HCC in an Asian cohort. Their results showed that this combination had a synergistic effect, with an ORR of $30.5 \%$ and with good safety and tolerability profiles [64]. 


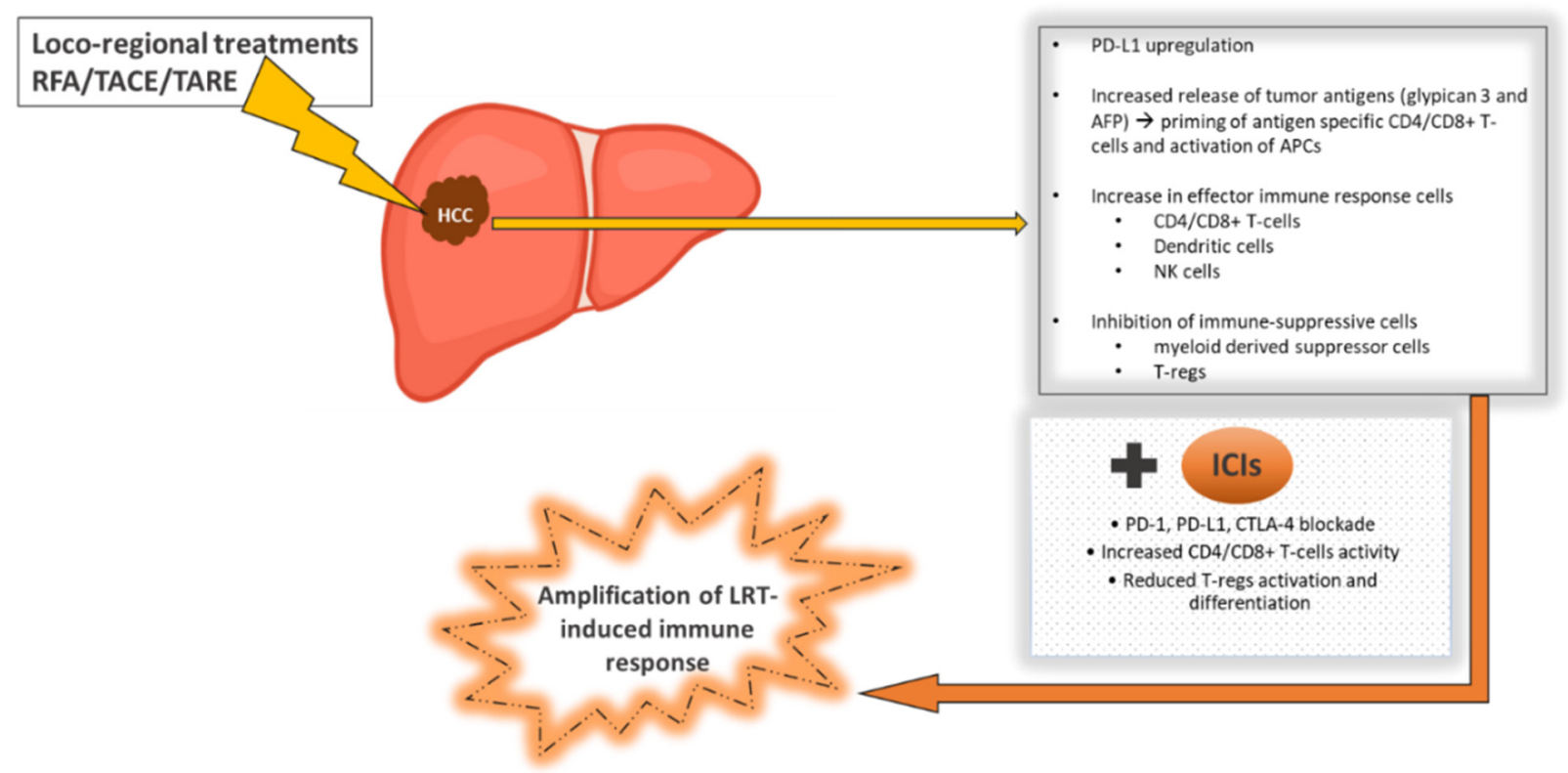

Figure 2. Locoregional treatments applied to hepatocellular carcinoma (HCC) induce immunological effects in the tumor microenvironment, which can be amplified by immune checkpoint inhibitors. After radiofrequency ablation (RFA) or trans-arterial chemo-embolization (TACE) or radio-embolization (TARE), necrosis of tumor cells induces increased tumorantigen release, thus facilitating the recruitment and activation of cytotoxic T-cells and dendritic cells. These effects can be exploited by administering immune checkpoint inhibitors (ICIs) to transform an immunosuppressive microenvironment in an immune-supportive one, in which systemic therapies might be more effective.

Based on these findings, several trials are ongoing to test the efficacy of combined ICIs and locoregional treatments in HCC. This strategy might significantly decrease recurrence rates after treatment with ablative techniques, thus ameliorating long-term prognosis of patients with very early/early HCC. Similarly, ICIs may potentially enhance responses after trans-arterial treatments; this implicates that patients with intermediate stage HCC may be effectively down-staged and might therefore become qualified for curative treatments. Hence, if ongoing studies in this field obtain good results in terms of safety and efficacy, ICIs would not only play a role in the setting of advanced HCC, but would also become a fundamental component of the management of the earlier stages of this tumor.

\section{Amenability to Atezolizumab Plus Bevacizumab in Real-Life Setting}

Given the expected upcoming change in the standard of care for the treatment of patients with advanced HCC, with a preferential use of the combination of atezolizumab plus bevacizumab as first-line treatment, we aimed to explore the actual estimates of the potential applicability in clinical practice of this dual treatment in the Western HCC population. In order to do so, we applied the inclusion and exclusion criteria of the atezolizumab plus bevacizumab IMBrave- 150 study to the HCC population recorded in the Italian Liver Cancer (ITA.LI.CA) database. We used this database as it is representative of the real-life setting of HCC patients in Italy: the ITA.LI.CA database, indeed, includes more than 10,000 patients with newly diagnosed or recurrent HCC, with various underlying liver disease etiologies at all stages, who are managed in a large number of Italian centers with different levels of expertise (secondary and tertiary referral centers). Thus, it provides a reliable insight into the characteristics of HCC patients in Western regions and allows for predicting figures of the potential utilization of newly available HCC drugs in real-life clinical practice [39].

In order to carry this out, within the ITA.LI.CA database, we excluded patients diagnosed before 2008 - that is the year of availability of sorafenib in clinical practice in Italy - and we applied the inclusion and exclusion criteria, listed in Table 2, set forth in the Phase III IMbrave-150 trial in patients with advanced HCC. In the studied period 
(2008-2019), 7529 cases of HCC were reported overall and, among them, a total of 5203 cases had a newly diagnosed HCC, whereas 2326 presented the first recurrence after surgery and/or locoregional treatment; we then calculated the eligibility rate to atezolizumab plus bevacizumab in the overall cohort and, separately, in the two subgroups of naïve patients with HCC or with an HCC recurrence after surgery or locoregional treatment (Figure 3).

Table 2. Criteria of eligibility for the management of unresectable HCC with atezolizumab plus bevacizumab as a first-line therapy.

IMBrave-150 Inclusion Criteria
Age $\geq 18$ years
Locally advanced or metastatic and/or unresectable HCC
No prior systemic therapy for HCC
disease after surgical and/or locoregional therapies
At least one measurable (per RECIST 1.1) untreated lesion
Disease that is not amenable to curative surgical and/or locoregional therapies, or prome
Patients who received prior local therapy (e.g., radiofrequency ablation, percutaneous ethanol or
acetic acid injection, cryoablation, high-intensity focused ultrasound, transarterial
chemoembolization, transarterial embolization, etc.) are eligible provided the target lesion(s) have
not been previously treated with local therapy or the target lesion(s) within the field of local
therapy have subsequently progressed in accordance with RECIST version 1.1
ECOG PS 0-1

Child-Pugh class A

ANC $\geq 1.5 \times 10^{9} / \mathrm{L}(1500 / \mathrm{mcL})$ without granulocyte colony-stimulating factor support Lymphocyte count $\geq 0.5 \times 109 / \mathrm{L}(500 / \mu \mathrm{L})$

Platelet count $\geq 75 \times 109 / \mathrm{L}(75,000 / \mu \mathrm{L})$ without transfusion Hemoglobin $\geq 90 \mathrm{~g} / \mathrm{L}(9 \mathrm{~g} / \mathrm{dL})$

AST, ALT, and alkaline phosphatase (ALP) $\leq 5 \times$ upper limit of normal (ULN) Serum bilirubin $\leq 3 \times$ ULN

Serum creatinine $\leq 1.5 \times$ ULN or creatinine clearance $\geq 50 \mathrm{~mL} / \mathrm{min}$ (Cockcroft-Gault formula) Serum albumin $\geq 28 \mathrm{~g} / \mathrm{L}$

For patients not receiving therapeutic anticoagulation: INR or aPTT $\leq-2 \times$ ULN Urine dipstick for proteinuria $<2+$ Negative HIV test at screening

In case of active $\mathrm{HBV}, \mathrm{HBV}$ DNA $<500 \mathrm{IU} / \mathrm{mL}$ and anti-HBV treatment for a minimum of 14 days prior to study entry

No history of leptomeningeal disease

No active or history of autoimmune disease or immune deficiency

No history of idiopathic pulmonary fibrosis, organizing pneumonia, drug-induced pneumonitis, or idiopathic pneumonitis, or evidence of active pneumonitis No active tuberculosis

No significant cardiovascular disease ( $\geq$ NYHA Class II)

No major surgical procedure, other than for diagnosis, within 4 weeks

No history of malignancy other than HCC within 5 years prior to screening

No severe infection within 4 weeks prior to initiation of study treatment

No treatment with therapeutic oral or IV antibiotics within 2 weeks prior to initiation of study treatment

No prior allogeneic stem cell or solid organ transplantation

No known fibrolamellar HCC, sarcomatoid HCC, or mixed cholangiocarcinoma and HCC No untreated or incompletely treated varices with bleeding or high risk for bleeding No moderate or severe ascites No history of hepatic encephalopathy

No co-infection of HBV and HCV

No symptomatic, untreated, or actively progressing central nervous system (CNS) metastases No uncontrolled pleural effusion, pericardial effusion, or ascites requiring recurrent drainage procedures

No uncontrolled or symptomatic hypercalcemia

No treatment with systemic immunosuppressive medication

No inadequately controlled arterial hypertension

No significant vascular disease

No history of intra-abdominal inflammatory process 


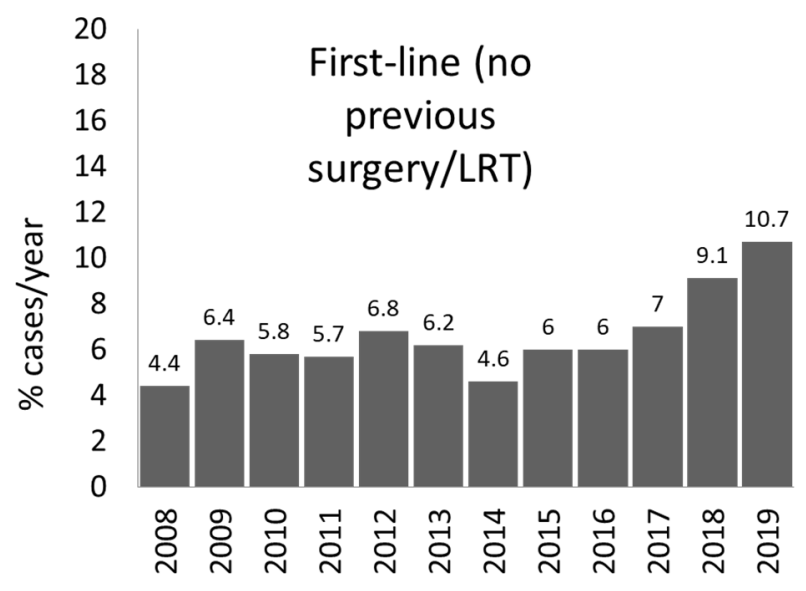

(A)

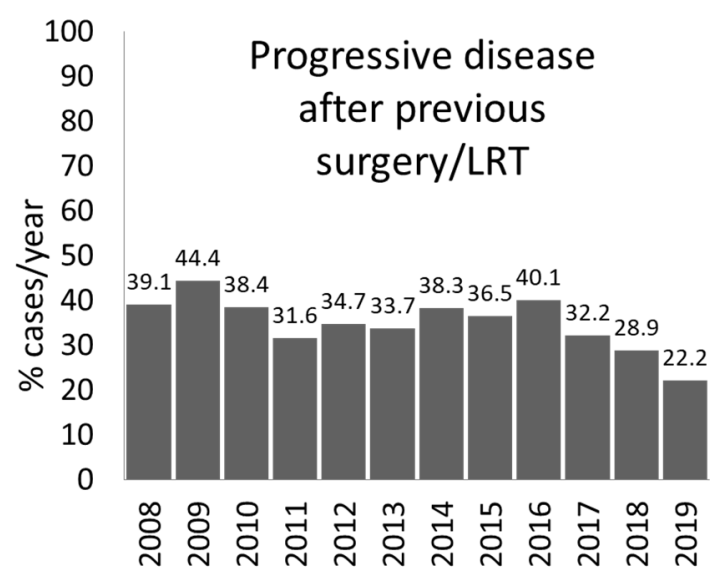

(B)

Figure 3. (A,B) Proportion of patients with new onset HCC or with HCC recurrence after surgery or locoregional treatment, which is amenable to first-line treatment with atezolizumab plus bevacizumab, per year, in the ITA.LI.CA database.

As far as the subgroup of naive patients with HCC is concerned, the overall proportion of patients deemed eligible for atezolizumab plus bevacizumab was $7.1 \%$, ranging from $5.3 \%$ to $5.4 \%$ (2008-2014) up to $10.7 \%$ (2019), with a median eligibility rate for the novel therapy in this group of patients of $7.5 \%$, and with an increasing trend observed in the most recent years (Figure 3A). With regard to patients with HCC recurrence after surgery or locoregional treatment, after excluding those not eligible for the treatment with atezolizumab plus bevacizumab as per the study inclusion and exclusion criteria, the overall eligibility rate to this ICI-based therapy was $36.3 \%$, with a median eligibility rate across the whole period of $36.5 \%$ (range, $28.9 \%$ to $44.4 \%$ ), with a decreasing trend observed in the most recent years (Figure 3B).

Taking into account all the patients included in the ITA.LI.CA database in the period 2008-2019, irrespective of previous locoregional treatment, approximately $16 \%$ of cases were considered eligible for the newly approved dual treatment. This figure is in accordance with estimates from other reports on ICI-based treatments [39].

Among patients with newly diagnosed HCC, $1.4 \%$ of patients were excluded solely due to the presence of untreated, or incompletely treated, esophageal varices at high risk of bleeding, while this figure among patients with recurrence following locoregional treatment or surgery was $4.0 \%$. However, the presence of esophageal varices at high risk of bleeding should not be considered a strict exclusion criterion, as primary prevention of variceal bleeding can and must be performed with either non-selective beta-blockers or endoscopic banding ligation as part of the standard of care of patients with cirrhosis [51,52]. Ligation, which might be preferred due to the possibility of an objective assessment of treatment success, may delay by several weeks the beginning of anti-tumor treatment due to the need to fully evaluate the eradication of varices in a proportion of patients ranging from $1.4 \%$ to $4.0 \%$. These considerations need to be taken into account in the therapeutic decision process, as overall approximately $13 \%$ of patients with HCC harbor large esophageal varices, a finding keeping with the overall prevalence of at-risk varices in this study population (i.e., $15.0 \%$ ) before the application of the inclusion/exclusion criteria of the atezolizumab plus bevacizumab study [65]. Moreover, besides representing an issue to be solved before the beginning of treatment, the presence of varices has an inherent meaning that needs to be underscored in these patients, as it pinpoints a subpopulation of patients that-despite having similar inclusion criteria—presents a more advanced liver disease, characterized by clinically significant portal hypertension. This finding is not negligible when patients' prognosis is assessed, as the presence of esophageal varices is an independent prognostic determinant, also considering the stage of liver disease and HCC stage $[51,65-67]$. Therefore, the prognosis of patients with advanced HCC and esophageal 
varices will be poorer than that of patients without varices, regardless of the efficacy of the anti-tumoral drug (Figure 4) [65]; as such, screening and treatment (either with band ligation or beta-blockers, selected on a case by case basis) is strongly recommended and must be performed in all patients with HCC, independently from the tumor stage and prior to the initiation of any anti-tumoral treatment.

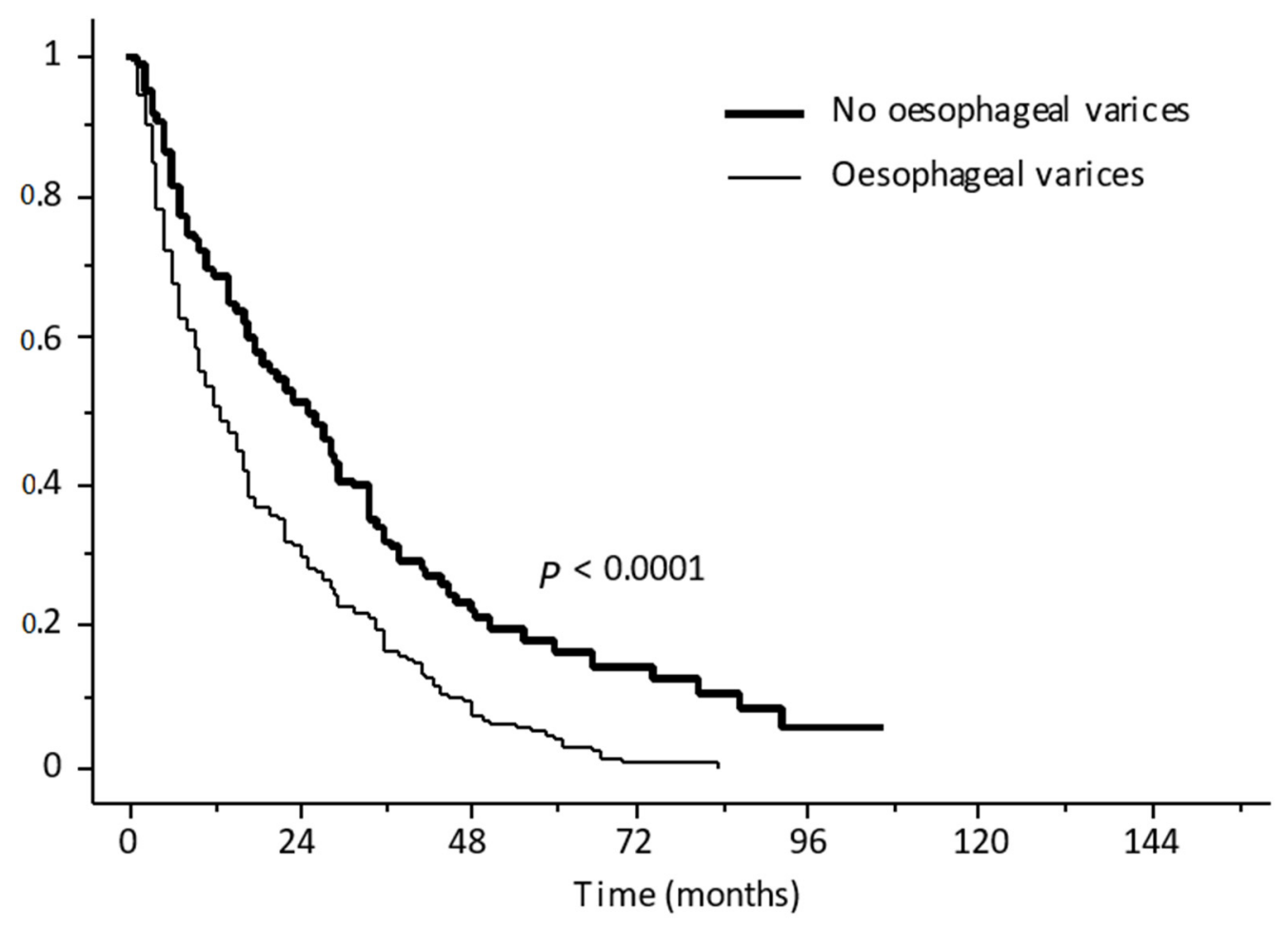

Figure 4. Overall survival of patients with advanced hepatocellular carcinoma, subdivided according to the presence of esophageal varices. Reprinted with permission from ref. [65]. Copyright 2006 American Gastroenterological Association.

\section{Conclusions}

Immunotherapy certainly represents a new, exciting frontier in the treatment of advanced, unresectable HCC, and might play a role as an adjuvant or neo-adjuvant treatment of patients with early-stage HCC as well, giving them the chance to decrease the risk of tumor recurrence. New ICI-based treatment strategies with dual, or even triple, combinations of immune-targeting agents, or combinations of immunotherapy and TKIs or other anti-neoplastic agents, will probably be available in the foreseeable future. Thus, it is currently difficult to predict the future algorithm for the systemic treatment of advanced HCC and to state whether sorafenib and lenvatinib, as single agents, will still be listed among the first-line treatment options for this cancer. However, despite the understandable enthusiasm for immunotherapy, some unmet needs remain and require further, extensive research to be resolved. First, as many as $30-40 \%$ of patients with HCC do not respond to ICIs, and biomarkers predicting treatment response are lacking. This is a particular challenging issue as data about histological or serological biomarkers related to the effectiveness of ICIs in HCC have not been clearly identified, and, even if a histological marker was identified, biopsy sampling of HCC is not standard clinical practice for this tumor, which is mostly diagnosed on the basis of its radiological hallmarks; therefore, in the future, the role of liver biopsy in HCC might need to be revisited [68]. Secondly, we have shown that in real-life, also taking into consideration previous treatments, only approximately one-tenth to one-third of patients with HCC are eligible for the recently approved combination of atezolizumab plus bevacizumab. Moreover, the safety and utility of immunotherapy in patients with a greater impairment in liver function, such as Child-Pugh class B patients, still has to be demonstrated, as most trials have explored the safety of these drugs in 
patients with well-preserved liver function (Child-Pugh class A) and, even though some reports have described an acceptable safety profile of some ICIs in Child-Pugh class B patients, consistent data regarding this topic are lacking, so that no strong recommendation can be made in this regard for the time being. Finally, ICIs are highly expensive drugs and this may represent a serious threat to the worldwide treatment implementation in clinical practice, since a large share of patients with HCC are diagnosed in developing countries, where available economic resources cannot support their use [69].

Taken together, the available evidence clearly shows that ICIs are going to play a pivotal role in the treatment of HCC and will improve the prognosis of patients with advanced HCC and, presumably, of those at earlier stages of the disease as well. We can assume that in the foreseeable future the current treatment algorithms will need revisions based on the most recent evidence. However, considering that in real-life settings a high proportion of patients will probably not be eligible for ICI-based regimens, much effort is still needed in order to optimize treatment strategies for patients with advanced, unresectable HCC.

Funding: This research received no external funding.

Institutional Review Board Statement: Not applicable.

Informed Consent Statement: Not applicable.

Data Availability Statement: Data available on request due to restrictions. The data presented in this study are available on request from the corresponding author. The data are not publicly available due to the rules of the ITA.LI.CA consortium.

Acknowledgments: We acknowledged Italian Liver Cancer (ITA.LI.CA) Group and the Italian Association for the Study of the Liver-Hepatocellular Carcinoma Special Interest Group (AISF HCC-SIG). Others members of the ITA.LI.CA group: Maurizio Biselli, Laura Bucci, Paolo Caraceni, Annagiulia Gramenzi, Lorenzo Lani, Davide Rampoldi, Nicola Reggidori, Valentina Santi, Benedetta Stefanini: Semeiotics Unit, Department of Medical and Surgical Sciences, IRCCS Azienda OspedalieroUniversitaria di Bologna, University of Bologna, Bologna, Italy. Donatella Magalotti, Marco Zoli: Medicina Interna, Malattie neurovascolari e epatometaboliche, IRCCS Azienda Ospedaliero-Universitaria di Bologna, University of Bologna, Bologna, Italy. Alessandro Granito, Luca Muratori, Francesco Tovoli: Internal Medicine, Department of Medical and Surgical Sciences, IRCCS Azienda Ospedaliero-Universitaria di Bologna, University of Bologna, Bologna, Italy. Francesco Azzaroli, Elton Dajti, Federico Ravaioli: Gastroenterology Unit, Department of Surgical and Medical Sciences, IRCCS Azienda Ospedaliero-Universitaria di Bologna, University of Bologna, Bologna, Italy. Alberta Cappelli, Rita Golfieri, Cristina Mosconi, Matteo Renzulli: Radiology Unit, Department of Specialist, Diagnostic and Experimental Medicine, IRCCS Azienda Ospedaliero-Universitaria di Bologna, University of Bologna, Bologna, Italy. Fabio Farinati, Barbara Penzo: Gastroenterology Unit, Department of Surgery, Oncology and Gastroenterology, University of Padova, Padova, Italy. Rodolfo Sacco, Ester Marina Cela, Antonio Facciorusso: Gastroenterology and Digestive Endoscopy Unit, Foggia University Hospital, Foggia, Italy. Giulia Pieri, Edoardo Casagrande, Mattia Vanello. Gastroenterology Unit, Department of Internal Medicine, IRCCS Ospedale Policlinico San Martino, University of Genova, Genova, Italy. Antonio Gasbarrini, Gianludovico Rapaccini, Francesca Romana Ponziani, Nicoletta de Matthaeis: Gastroenterology Unit, IRCCS Fondazione Policlinico Universitario A. Gemelli, Roma, Italy. Gianluca Svegliati Baroni, Gloria Allegrini: Liver Injury and Transplant Unit, Polytechnic University of Marche, Ancona, Italy. Valentina Lauria, Giorgia Ghittoni, Giorgio Pelecca: Gastroenterology Unit, Belcolle Hospital, Viterbo, Italy. Fabrizio Chegai, Fabio Coratella, Mariano Ortenzi: Vascular and Interventional Radiology Unit, Belcolle Hospital, Viterbo, Italy. Serena Dell'Isola: Infectious Disease Unit, Belcolle Hospital, Viterbo, Italy. Gabriele Missale, Elisabetta Biasini, Andrea Olivani: Infectious Diseases and Hepatology Unit, Department of Medicine and Surgery, University of Parma and Azienda Ospedaliero-Universitaria of Parma, Parma, Italy. Alberto Masotto, Alessandro Inno, Fabiana Marchetti: Gastroenterology Unit, IRCCS Sacro Cuore Don Calabria Hospital, Negrar, Italy. Maria Di Marco: Medicine Unit, Bolognini Hospital, Seriate, Italy. Andrea Mega: Gastroenterology Unit, Bolzano Regional Hospital, Bolzano, Italy. Ciro Celsa, Mauro Grova, Caterina Stornello, Anita Busacca, Calogero Cammà, Giacomo Emanuele Maria Rizzo: Gastroenterology and Hepatology Unit, Department of Health Promotion, Mother and Child Care, Internal Medicine and Medical Specialties, PROMISE, University of Palermo, Palermo, Italy. Maria Stella Franzè, Giovanni Raimondo, 
Carlo Saitta: Clinical and Molecular Hepatology Unit, Department of Clinical and Experimental Medicine, University of Messina, Messina, Italy. Gianpaolo Vidili, Assunta Sauchella: Department of Medical, Surgical and Experimental Sciences, Azienda Ospedaliero-Universitaria of Sassari, Sassari, Italy. Francesco Giuseppe Foschi, Lucia Napoli, Vittoria Bevilacqua, Dante Berardinelli, Alberto Borghi, Andrea Casadei Gardini, Fabio Conti, Alessandro Cucchetti, Anna Chiara Dall'Aglio, Giorgio Ercolani: Department of Internal Medicine, Ospedale per gli Infermi di Faenza, Faenza, Italy. Claudia Campani, Chiara Di Bonaventura, Stefano Gitto, Valentina Adotti: Internal Medicine and Hepatology Unit, Department of Experimental and Clinical Medicine, University of Firenze, Firenze, Italy. Gerardo Nardone, Pietro Coccoli, Antonio Malerba: Hepato-Gastroenterology Unit, Department of Clinical Medicine and Surgery, University of Napoli "Federico II", Napoli, Italy. Filomena Morisco, Maria Guarino, Mario Capasso: Gastroenterology Unit, Department of Clinical Medicine and Surgery, University of Napoli "Federico II", Napoli, Italy. Mauriza Rossana Brunetto, Filippo Oliveri, Veronica Romagnoli: Hepatology and Liver Physiopathology Laboratory, Department of Clinical and Experimental Medicine, University Hospital of Pisa, Pisa, Italy. Members of the Associazione Italiana per lo Studio del Fegato Special Interest Group on Hepatocellular Carcinoma (AISF SIG-HCC): Aglitti A., Baccarani U.,Bhoori S., Borzio M., Brancaccio G., Burra P., Carrai P., Conti F., Cozzolongo R, Cucchetti A., D'Ambrosio R., Dell’Unto C., De Matthaeis N., Di Costanzo G.G., Di Sandro S., Famularo S, Fucilli F., Galati G., Gambato M., Giuliante F., Ghinolfi D., Grieco A., Gruttadauria S., Iavarone M., Kostandini A., Lenci I., Levi Sandri G.V., Losito F., Lupo L.G., Marasco G, Manzia T.M., Mazzocato S., Masarone M., Melandro F., Mescoli C., Miele L., Muley M., Nicolini D., Pagano D, Persico M., Pompili M., Pravisani R., Rendina M., Renzulli M., Romano F, Rossi M., Rreka E., Russo F.P., Sangiovanni A., Sessa A., Simonetti N., Sposito C., Tortora R., Viganò L., Viganò M., Villa E., Vincenzi V., Violi P., Vitale A.

Conflicts of Interest: The authors declare no conflict of interest.

\section{References}

1. Villanueva, A. Hepatocellular Carcinoma. N. Engl. J. Med. 2019, 380, 1450-1462. [CrossRef]

2. Mittal, S.; El-Serag, H.B.; Sada, Y.H.; Kanwal, F.; Duan, Z.; Temple, S.; May, S.; Kramer, J.R.; Richardson, P.A.; Davila, J.A. Hepatocellular Carcinoma in the Absence of Cirrhosis in United States Veterans Is Associated with Nonalcoholic Fatty Liver Disease. Clin. Gastroenterol. Hepatol. 2016, 14, 124-131.e1. [CrossRef]

3. Kanwal, F.; Kramer, J.R.; Mapakshi, S.; Natarajan, Y.; Chayanupatkul, M.; Richardson, P.A.; Li, L.; Desiderio, R.; Thrift, A.P.; Asch, S.M.; et al. Risk of Hepatocellular Cancer in Patients with Non-Alcoholic Fatty Liver Disease. Gastroenterology 2018, 155, 1828-1837.e2. [CrossRef] [PubMed]

4. Torres, M.C.P.; Bodini, G.; Furnari, M.; Marabotto, E.; Zentilin, P.; Strazzabosco, M.; Giannini, E.G. Surveillance for Hepatocellular Carcinoma in Patients with Non-Alcoholic Fatty Liver Disease: Universal or Selective? Cancers 2020, 12, 1422. [CrossRef]

5. Torres, M.C.P.; Aghemo, A.; Lleo, A.; Bodini, G.; Furnari, M.; Marabotto, E.; Miele, L.; Giannini, E.G. Mediterranean Diet and NAFLD: What We Know and Questions That Still Need to Be Answered. Nutrients 2019, 11, 2971. [CrossRef]

6. Llovet, J.M.; Ricci, S.; Mazzaferro, V.; Hilgard, P.; Gane, E.; Blanc, J.F.; De Oliveira, A.C.; Santoro, A.; Raoul, J.L.; Forner, A.; et al. Sorafenib in Advanced Hepatocellular Carcinoma. N. Engl. J. Med. 2008, 359, 378-390. [CrossRef]

7. Cheng, A.-L.; Kang, Y.-K.; Chen, Z.; Tsao, C.-J.; Qin, S.; Kim, J.S.; Luo, R.; Feng, J.; Ye, S.; Yang, T.-S.; et al. Efficacy and safety of sorafenib in patients in the Asia-Pacific region with advanced hepatocellular carcinoma: A phase III randomised, double-blind, placebo-controlled trial. Lancet Oncol. 2009, 10, 25-34. [CrossRef]

8. Cheng, A.-L.; Finn, R.S.; Qin, S.; Han, K.-H.; Ikeda, K.; Piscaglia, F.; Baron, A.D.; Park, J.-W.; Han, G.; Jassem, J.; et al. Phase III trial of lenvatinib (LEN) vs sorafenib (SOR) in first-line treatment of patients (pts) with unresectable hepatocellular carcinoma (uHCC). J. Clin. Oncol. 2017, 35, 4001. [CrossRef]

9. Kirstein, M.M.; Scheiner, B.; Marwede, T.; Wolf, C.; Voigtländer, T.; Semmler, G.; Wacker, F.; Manns, M.P.; Hinrichs, J.B.; Pinter, M.; et al. Sequential systemic treatment in patients with hepatocellular carcinoma. Aliment. Pharmacol. Ther. 2020, 52, $205-212$. [CrossRef] [PubMed]

10. Sangro, B.; Gomez-Martin, C.; de la Mata, M.; Iñarrairaegui, M.; Garralda, E.; Barrera, P.; Riezu-Boj, J.-I.; Larrea, E.; Alfaro, C.; Sarobe, P.; et al. A clinical trial of CTLA-4 blockade with tremelimumab in patients with hepatocellular carcinoma and chronic hepatitis C. J. Hepatol. 2013, 59, 81-88. [CrossRef]

11. El-Khoueiry, A.B.; Sangro, B.; Yau, T.C.C.; Crocenzi, T.S.; Kudo, M.; Hsu, C.; Kim, T.-Y.; Choo, S.-P.; Trojan, J.; Welling, T.H.; et al. Nivolumab in patients with advanced hepatocellular carcinoma (CheckMate 040): An open-label, non-comparative, phase $1 / 2$ dose escalation and expansion trial. Lancet 2017, 389, 2492-2502. [CrossRef]

12. Zhu, A.X.; Finn, R.S.; Edeline, J.; Cattan, S.; Ogasawara, S.; Palmer, D.; Verslype, C.; Zagonel, V.; Fartoux, L.; Vogel, A.; et al. Pembrolizumab in patients with advanced hepatocellular carcinoma previously treated with sorafenib (KEYNOTE-224): A non-randomised, open-label phase 2 trial. Lancet Oncol. 2018, 19, 940-952. [CrossRef] 
13. Finn, R.S.; Ryoo, B.-Y.; Merle, P.; Kudo, M.; Bouattour, M.; Lim, H.Y.; Breder, V.; Edeline, J.; Chao, Y.; Ogasawara, S.; et al. Pembrolizumab As Second-Line Therapy in Patients with Advanced Hepatocellular Carcinoma in KEYNOTE-240: A Randomized, Double-Blind, Phase III Trial. J. Clin. Oncol. 2020, 38, 193-202. [CrossRef] [PubMed]

14. Yau, T.; Park, J.W.; Finn, R.S.; Cheng, A.L.; Mathurin, P.; Edeline, J.; Kudo, M.; Han, K.H.; Harding, J.J.; Merle, P.; et al. CheckMate 459: A randomized, multi-center phase III study of nivolumab (NIVO) vs sorafenib (SOR) as first-line (1L) treatment in patients (pts) with advanced hepatocellular carcinoma (aHCC). Ann. Oncol. 2019, 30, v874-v875. [CrossRef]

15. Finn, R.S.; Qin, S.; Ikeda, M.; Galle, P.R.; Ducreux, M.; Kim, T.-Y.; Kudo, M.; Breder, V.; Merle, P.; Kaseb, A.O. Atezolizumab plus Bevacizumab in Unresectable Hepatocellular Carcinoma. N. Engl. J. Med. 2020, 382, 1894-1905. [CrossRef]

16. Iavarone, M.; Cabibbo, G.; Piscaglia, F.; Zavaglia, C.; Grieco, A.; Villa, E.; Camma', C.; Colombo, M.; on behalf of the SOFIA (SOraFenib Italian Assessment) study group. Field-practice study of sorafenib therapy for hepatocellular carcinoma: A prospective multicenter study in Italy. Hepatology 2011, 54, 2055-2063. [CrossRef] [PubMed]

17. Ganten, T.M.; Stauber, R.E.; Schott, E.; Malfertheiner, P.; Buder, R.; Galle, P.R.; Göhler, T.; Walther, M.; Koschny, R.; Gerken, G. Sorafenib in Patients with Hepatocellular Carcinoma-Results of the Observational INSIGHT Study. Clin. Cancer Res. 2017, 23, 5720-5728. [CrossRef]

18. Bruix, J.; Qin, S.; Merle, P.; Granito, A.; Huang, Y.-H.; Bodoky, G.; Pracht, M.; Yokosuka, O.; Rosmorduc, O.; Breder, V.; et al. Regorafenib for patients with hepatocellular carcinoma who progressed on sorafenib treatment (RESORCE): A randomised, double-blind, placebo-controlled, phase 3 trial. Lancet 2017, 389, 56-66. [CrossRef]

19. Zhu, A.X.; Kang, Y.-K.; Yen, C.-J.; Finn, R.S.; Galle, P.R.; Llovet, J.M.; Assenat, E.; Brandi, G.; Lim, H.Y.; Pracht, M.; et al. REACH-2: A randomized, double-blind, placebo-controlled phase 3 study of ramucirumab versus placebo as second-line treatment in patients with advanced hepatocellular carcinoma (HCC) and elevated baseline alpha-fetoprotein (AFP) following first-line sorafenib. J. Clin. Oncol. 2018, 36, 4003. [CrossRef]

20. Abou-Alfa, G.K.; Meyer, T.; Cheng, A.-L.; El-Khoueiry, A.B.; Rimassa, L.; Ryoo, B.-Y.; Cicin, I.; Merle, P.; Chen, Y.; Park, J.-W.; et al Cabozantinib in Patients with Advanced and Progressing Hepatocellular Carcinoma. N. Engl. J. Med. 2018, 379, 54-63. [CrossRef]

21. Zhu, A.X.; Park, J.O.; Ryoo, B.-Y.; Yen, C.-J.; Poon, R.; Pastorelli, D.; Blanc, J.-F.; Chung, H.; Baron, A.D.; Pfiffer, T.E.F.; et al. Ramucirumab versus placebo as second-line treatment in patients with advanced hepatocellular carcinoma following first-line therapy with sorafenib (REACH): A randomised, double-blind, multicentre, phase 3 trial. Lancet Oncol. 2015, 16, 859-870. [CrossRef]

22. Giannini, E.G.; Trevisani, F. Ramucirumab as a second-line treatment for hepatocellular carcinoma: Reaching out further to patients with elevated alpha-fetoprotein. Hepatobiliary Surg. Nutr. 2019, 8, 515-518. [CrossRef]

23. Lai, E.; Astara, G.; Ziranu, P.; Pretta, A.; Migliari, M.; Dubois, M.; Donisi, C.; Mariani, S.; Liscia, N.; Impera, V.; et al. Introducing immunotherapy for advanced hepatocellular carcinoma patients: Too early or too fast? Crit. Rev. Oncol. 2021, 157, 103167. [CrossRef]

24. Garuti, F.; Neri, A.; Avanzato, F.; Gramenzi, A.; Rampoldi, D.; Rucci, P.; Farinati, F.; Giannini, E.G.; Piscaglia, F.; Rapaccini, G.L.; et al. The changing scenario of hepatocellular carcinoma in Italy: An update. Liver Int. 2021, 41, 585-597. [CrossRef]

25. Hoshida, Y.; Villanueva, A.; Kobayashi, M.; Peix, J.; Chiang, D.Y.; Camargo, A.; Gupta, S.; Moore, J.; Wrobel, M.J.; Lerner, J.; et al. Gene Expression in Fixed Tissues and Outcome in Hepatocellular Carcinoma. N. Engl. J. Med. 2008, 359, 1995-2004. [CrossRef]

26. Pikarsky, E.; Porat, R.M.; Stein, I.; Abramovitch, R.; Amit, S.; Kasem, S.; Gutkovich-Pyest, E.; Urieli-Shoval, S.; Galun, E.; Ben-Neriah, Y. NF-kB functions as a tumour promoter in inflammation-associated cancer. Nature 2004, 431, 461-466. [CrossRef]

27. Llovet, J.M.; Montal, R.; Sia, D.; Finn, R.S. Molecular therapies and precision medicine for hepatocellular carcinoma. Nat. Rev. Clin. Oncol. 2018, 15, 599-616. [CrossRef] [PubMed]

28. Prieto, J.; Melero, I.; Sangro, B. Immunological landscape and immunotherapy of hepatocellular carcinoma. Nat. Rev. Gastroenterol. Hepatol. 2015, 12, 681-700. [CrossRef] [PubMed]

29. Shi, F.; Shi, M.; Zeng, Z.; Qi, R.-Z.; Liu, Z.-W.; Zhang, J.-Y.; Yang, Y.-P.; Tien, P.; Wang, F.-S. PD-1 and PD-L1 upregulation promotes CD8+ T-cell apoptosis and postoperative recurrence in hepatocellular carcinoma patients. Int. J. Cancer 2010, 128, 887-896. [CrossRef] [PubMed]

30. Sia, D.; Jiao, Y.; Martinez-Quetglas, I.; Kuchuk, O.; Villacorta-Martin, C.; de Moura, M.C.; Putra, J.; Campreciós, G.; Bassaganyas, L.; Akers, N.; et al. Identification of an Immune-specific Class of Hepatocellular Carcinoma, Based on Molecular Features. Gastroenterology 2017, 153, 812-826. [CrossRef] [PubMed]

31. Chen, D.S.; Mellman, I. Oncology Meets Immunology: The Cancer-Immunity Cycle. Immunity 2013, 39, 1-10. [CrossRef]

32. Ringelhan, M.; Pfister, D.; O'Connor, T.; Pikarsky, E.; Heikenwalder, M. The immunology of hepatocellular carcinoma. Nat. Immunol. 2018, 19, 222-232. [CrossRef]

33. Postow, M.A.; Callahan, M.K.; Wolchok, J.D. Immune Checkpoint Blockade in Cancer Therapy. J. Clin. Oncol. 2015, 33, 1974-1982. [CrossRef] [PubMed]

34. El-Khoueiry, A.B.; Melero, I.; Yau, T.C.; Crocenzi, T.S.; Kudo, M.; Hsu, C.; Choo, S.; Trojan, J.; Welling, T.; Meyer, T.; et al. Impact of antitumor activity on survival outcomes, and nonconventional benefit, with nivolumab (NIVO) in patients with advanced hepatocellular carcinoma (aHCC): Subanalyses of CheckMate-040. J. Clin. Oncol. 2018, 36, 475. [CrossRef]

35. Crocenzi, T.S.; El-Khoueiry, A.B.; Yau, T.C.; Melero, I.; Sangro, B.; Kudo, M.; Hsu, C.; Trojan, J.; Kim, T.-Y.; Choo, S.-P.; et al. Nivolumab (nivo) in sorafenib (sor)-naive and -experienced pts with advanced hepatocellular carcinoma (HCC): CheckMate 040 study. J. Clin. Oncol. 2017, 35, 4013. [CrossRef] 
36. Abou-Alfa, G.K.; Chan, S.; Furuse, J.; Galle, P.R.; Kelley, R.K.; Qin, S.; Armstrong, J.; Darilay, A.; Vlahovic, G.; Negro, A.; et al. A randomized, multicenter phase 3 study of durvalumab (D) and tremelimumab (T) as first-line treatment in patients with unresectable hepatocellular carcinoma (HCC): HIMALAYA study. J. Clin. Oncol. 2018, 36, TPS4144. [CrossRef]

37. Kudo, M.; Matilla, A.; Santoro, A.; Melero, I.; Gracian, A.C.; Acosta-Rivera, M.; Choo, S.P.; El-Khoueiry, A.B.; Kuromatsu, R.; El-Rayes, B.F.; et al. Checkmate-040: Nivolumab (NIVO) in patients (pts) with advanced hepatocellular carcinoma (aHCC) and Child-Pugh B (CPB) status. J. Clin. Oncol. 2019, 37, 327. [CrossRef]

38. Haanen, J.; Carbonnel, F.; Robert, C.; Kerr, K.; Peters, S.; Larkin, J.; Jordan, K. Management of toxicities from immunotherapy: ESMO Clinical Practice Guidelines for diagnosis, treatment and follow-up. Ann. Oncol. 2017, 28, iv119-iv142. [CrossRef] [PubMed]

39. Giannini, E.G.; Aglitti, A.; Borzio, M.; Gambato, M.; Guarino, M.; Iavarone, M.; Lai, Q.; Sandri, G.B.L.; Melandro, F.; Morisco, F.; et al. Overview of Immune Checkpoint Inhibitors Therapy for Hepatocellular Carcinoma, and The ITA.LI.CA Cohort Derived Estimate of Amenability Rate to Immune Checkpoint Inhibitors in Clinical Practice. Cancers 2019, 11, 1689. [CrossRef]

40. De Velasco, G.; Je, Y.; Bossé, D.; Awad, M.M.; Ott, P.A.; Moreira, R.B.; Schutz, F.; Bellmunt, J.; Sonpavde, G.P.; Hodi, F.S.; et al. Comprehensive Meta-analysis of Key Immune-Related Adverse Events from CTLA-4 and PD-1/PD-L1 Inhibitors in Cancer Patients. Cancer Immunol. Res. 2017, 5, 312-318. [CrossRef]

41. Scheiner, B.; Kirstein, M.M.; Hucke, F.; Finkelmeier, F.; Schulze, K.; Von Felden, J.; Koch, S.; Schwabl, P.; Hinrichs, J.B.; Waneck, F.; et al. Programmed cell death protein-1 (PD-1)-targeted immunotherapy in advanced hepatocellular carcinoma: Efficacy and safety data from an international multicentre real-world cohort. Aliment. Pharmacol. Ther. 2019, 49, 1323-1333. [CrossRef]

42. Yau, T.; Kang, Y.-K.; Kim, T.-Y.; El-Khoueiry, A.B.; Santoro, A.; Sangro, B.; Melero, I.; Kudo, M.; Hou, M.-M.; Matilla, A.; et al. Nivolumab (NIVO) + ipilimumab (IPI) combination therapy in patients (pts) with advanced hepatocellular carcinoma (aHCC): Results from CheckMate. J. Clin. Oncol. 2019, 37 (Suppl. S15), 4012. [CrossRef]

43. Yau, T.; Kang, Y.-K.; Kim, T.-Y.; El-Khoueiry, A.B.; Santoro, A.; Sangro, B.; Melero, I.; Kudo, M.; Hou, M.-M.; Matilla, A.; et al. Efficacy and Safety of Nivolumab Plus Ipilimumab in Patients with Advanced Hepatocellular Carcinoma Previously Treated with Sorafenib. JAMA Oncol. 2020, 6, e204564. [CrossRef] [PubMed]

44. Kelley, R.K.; Sangro, B.; Harris, W.P.; Ikeda, M.; Okusaka, T.; Kang, Y.-K.; Qin, S.; Tai, W.M.D.; Lim, H.Y.; Yau, T.; et al. Efficacy, tolerability, and biologic activity of a novel regimen of tremelimumab (T) in combination with durvalumab (D) for patients (pts) with advanced hepatocellular carcinoma (aHCC). J. Clin. Oncol. 2020, 38, 4508. [CrossRef]

45. Tai, D.; Choo, S.P.; Chew, V. Rationale of Immunotherapy in Hepatocellular Carcinoma and Its Potential Biomarkers. Cancers 2019, 11, 1926. [CrossRef]

46. Liu, L.; Qin, S.; Zhang, Y. The Evolving Landscape of Checkpoint Inhibitor Combination Therapy in the Treatment of Advanced Hepatocellular Carcinoma. Target. Oncol. 2021, 16, 153-163. [CrossRef]

47. Yau, T.; Zagonel, V.; Santoro, A.; Acosta-Rivera, M.; Choo, S.P.; Matilla, A.; He, A.R.; Gracián, A.C.; El-Khoueiry, A.B.; Sangro, B.; et al. Nivolumab (NIVO) + ipilimumab (IPI) + cabozantinib (CABO) combination therapy in patients (pts) with advanced hepatocellular carcinoma (aHCC): Results from CheckMate 040. J. Clin. Oncol. 2020, 38, 478. [CrossRef]

48. Finn, R.S.; Ikeda, M.; Zhu, A.X.; Sung, M.W.; Baron, A.D.; Kudo, M.; Okusaka, T.; Kobayashi, M.; Kumada, H.; Kaneko, S.; et al. Phase Ib Study of Lenvatinib Plus Pembrolizumab in Patients with Unresectable Hepatocellular Carcinoma. J. Clin. Oncol. 2020, 38, 2960-2970. [CrossRef] [PubMed]

49. Pinter, M.; Ulbrich, G.; Sieghart, W.; Kölblinger, C.; Reiberger, T.; Li, S.; Ferlitsch, A.; Müller, C.; Lammer, J.; Peck-Radosavljevic, M. Hepatocellular Carcinoma: A Phase II Randomized Controlled Double-Blind Trial of Transarterial Chemoembolization in Combination with Biweekly Intravenous Administration of Bevacizumab or a Placebo. Radiology 2015, 277, 903-912. [CrossRef] [PubMed]

50. Siegel, A.B.; Cohen, E.I.; Ocean, A.; Lehrer, D.; Goldenberg, A.; Knox, J.J.; Chen, H.; Clark-Garvey, S.; Weinberg, A.; Mandeli, J.; et al. Phase II Trial Evaluating the Clinical and Biologic Effects of Bevacizumab in Unresectable Hepatocellular Carcinoma. J. Clin. Oncol. 2008, 26, 2992-2998. [CrossRef]

51. Angeli, P.; Bernardi, M.; Villanueva, C.; Francoz, C.; Mookerjee, R.; Trebicka, J.; Krag, A.; Laleman, W.; Gines, P. EASL Clinical Practice Guidelines for the management of patients with decompensated cirrhosis. J. Hepatol. 2018, 69, 406-460. [CrossRef]

52. Giannini, E.G.; Trevisani, F. Improving survival of cirrhosis patients with hepatocellular carcinoma through application of standard of care. Hepatology 2014, 60, 1446-1447. [CrossRef]

53. Iwamoto, H.; Shimose, S.; Noda, Y.; Shirono, T.; Niizeki, T.; Nakano, M.; Okamura, S.; Kamachi, N.; Suzuki, H.; Sakai, M.; et al. Initial Experience of Atezolizumab Plus Bevacizumab for Unresectable Hepatocellular Carcinoma in Real-World Clinical Practice. Cancers 2021, 13, 2786. [CrossRef] [PubMed]

54. Greten, T.F.; Duffy, A.G.; Korangy, F. Hepatocellular Carcinoma from an Immunologic Perspective. Clin. Cancer Res. 2013, 19, 6678-6685. [CrossRef] [PubMed]

55. Singh, P.; Toom, S.; Avula, A.; Kumar, V.; E Rahma, O. The Immune Modulation Effect of Locoregional Therapies and Its Potential Synergy with Immunotherapy in Hepatocellular Carcinoma. J. Hepatocell. Carcinoma 2020, 7, 11-17. [CrossRef] [PubMed]

56. Duffy, A.G.; Ulahannan, S.; Makorova-Rusher, O.; Rahma, O.; Wedemeyer, H.; Pratt, D.; Davis, J.L.; Hughes, M.S.; Heller, T.; ElGindi, M.; et al. Tremelimumab in combination with ablation in patients with advanced hepatocellular carcinoma. J. Hepatol. 2017, 66, 545-551. [CrossRef] [PubMed] 
57. Ayaru, L.; Pereira, S.; Alisa, A.; Pathan, A.A.; Williams, R.; Davidson, B.; Burroughs, A.K.; Meyer, T.; Behboudi, S. Unmasking of $\alpha$-Fetoprotein-Specific CD4+ T Cell Responses in Hepatocellular Carcinoma Patients Undergoing Embolization. J. Immunol. 2007, 178, 1914-1922. [CrossRef]

58. Hänsler, J.; Hä, J.; Nsler, T.; Wissniowski, D.S.U.T. Activation and dramatically increased cytolytic activity of tumor specific T lymphocytes after radio-frequency ablation in patients with hepatocellular carcinoma and colorectal liver metastases. World J. Gastroenterol. 2006, 12, 3716-3721. [CrossRef] [PubMed]

59. Hiroishi, K.; Eguchi, J.; Baba, T.; Shimazaki, T.; Ishii, S.; Hiraide, A.; Sakaki, M.; Doi, H.; Uozumi, S.; Omori, R.; et al. Strong CD8+ T-cell responses against tumor-associated antigens prolong the recurrence-free interval after tumor treatment in patients with hepatocellular carcinoma. J. Gastroenterol. 2009, 45, 451-458. [CrossRef]

60. Mizukoshi, E.; Nakamoto, Y.; Arai, K.; Yamashita, T.; Sakai, A.; Sakai, Y.; Kagaya, T.; Yamashita, T.; Honda, M.; Kaneko, S. Comparative analysis of various tumor-associated antigen-specific t-cell responses in patients with hepatocellular carcinoma. Hepatology 2011, 53, 1206-1216. [CrossRef]

61. Zerbini, A.; Pilli, M.; Laccabue, D.; Pelosi, G.; Molinari, A.; Negri, E.; Cerioni, S.; Fagnoni, F.; Soliani, P.; Ferrari, C.; et al. Radiofrequency Thermal Ablation for Hepatocellular Carcinoma Stimulates Autologous NK-Cell Response. Gastroenterology 2010, 138, 1931-1942.e2. [CrossRef]

62. Kaseb, A.O.; Vence, L.; Blando, J.; Yadav, S.S.; Ikoma, N.; Pestana, R.C.; Vauthey, J.N.; Allison, J.P.; Sharma, P. Immunologic Correlates of Pathologic Complete Response to Preoperative Immunotherapy in Hepatocellular Carcinoma. Cancer Immunol. Res. 2019, 7, 1390-1395. [CrossRef] [PubMed]

63. Nakatsura, T.; Nobuoka, D.; Motomura, Y.; Shirakawa, H.; Yoshikawa, T.; Kuronuma, T.; Takahashi, M.; Nakachi, K.; Ishii, H.; Furuse, J.; et al. Radiofrequency ablation for hepatocellular carcinoma induces glypican-3 peptide-specific cytotoxic $\mathrm{T}$ lymphocytes. Int. J. Oncol. 2011, 40, 63-70. [CrossRef] [PubMed]

64. Tai, W.M.D.; Loke, K.S.H.; Gogna, A.; Tan, S.H.; Ng, D.C.E.; Hennedige, T.P.; Irani, F.; Lee, J.J.X.; Too, C.W.; Ng, M.C.; et al. A phase II open-label, single-center, nonrandomized trial of Y90-radioembolization in combination with nivolumab in Asian patients with advanced hepatocellular carcinoma: CA 209-678. J Clin. Oncol. 2020, 38, 4590. [CrossRef]

65. Giannini, E.G.; Risso, D.; Testa, R.; Trevisani, F.; Di Nolfo, M.A.; Del Poggio, P.; Benvegnù, L.; Rapaccini, G.L.; Farinati, F.; Zoli, M.; et al. Prevalence and Prognostic Significance of the Presence of Esophageal Varices in Patients with Hepatocellular Carcinoma. Clin. Gastroenterol. Hepatol. 2006, 4, 1378-1384. [CrossRef] [PubMed]

66. European Association for the Study of the Liver. EASL Clinical Practice Guidelines: Management of hepatocellular carcinoma. J. Hepatol. 2018, 69, 182-236. [CrossRef]

67. D’Amico, G.; Pasta, L.; Morabito, A.; Caltagirone, M.; Malizia, G.; Tinè, F.; Giannuoli, G.; Traina, M.; Vizzini, G.; Politi, F.; et al. Competing risks and prognostic stages of cirrhosis: A 25-year inception cohort study of 494 patients. Aliment. Pharmacol. Ther. 2014, 39, 1180-1193. [CrossRef]

68. Russo, F.P.; Imondi, A.; Lynch, E.N.; Farinati, F. When and how should we perform a biopsy for HCC in patients with liver cirrhosis in 2018? A review. Dig. Liver Dis. 2018, 50, 640-646. [CrossRef]

69. Dimitroulis, D.; Damaskos, C.; Valsami, S.; Davakis, S.; Garmpis, N.; Spartalis, E.; Athanasiou, A.; Moris, D.; Sakellariou, S.; Kykalos, S.; et al. From diagnosis to treatment of hepatocellular carcinoma: An epidemic problem for both developed and developing world. World J. Gastroenterol. 2017, 23, 5282-5294. [CrossRef] 